NBER WORKING PAPER SERIES

\title{
A MARKET BASED SOLUTION TO PRICE EXTERNALITIES: A GENERALIZED FRAMEWORK
}

\author{
Weerachart T. Kilenthong \\ Robert M. Townsend \\ Working Paper 20275 \\ http://www.nber.org/papers/w20275
NATIONAL BUREAU OF ECONOMIC RESEARCH
1050 Massachusetts Avenue
Cambridge, MA 02138
June 2014

Robert Townsend is grateful to financial support from the Eunice Kennedy Shriver National Institute of Child Health and Human Development (NICHD) under grant R01 HD027638, NSF, the John Templeton Foundation, and the Consortium on Financial Systems and Poverty at the University of Chicago through a grant from the Bill \& Melinda Gates Foundation. The findings and conclusions contained in the report are those of the author(s) and do not necessarily represent the views of the funders. The views expressed herein are those of the authors and do not necessarily reflect the views of the National Bureau of Economic Research.

NBER working papers are circulated for discussion and comment purposes. They have not been peerreviewed or been subject to the review by the NBER Board of Directors that accompanies official NBER publications.

(C) 2014 by Weerachart T. Kilenthong and Robert M. Townsend. All rights reserved. Short sections of text, not to exceed two paragraphs, may be quoted without explicit permission provided that full credit, including $\odot$ notice, is given to the source. 
A Market Based Solution to Price Externalities: A Generalized Framework

Weerachart T. Kilenthong and Robert M. Townsend

NBER Working Paper No. 20275

June 2014

JEL No. D52,D53,D61,D62

\begin{abstract}
$\underline{\text { ABSTRACT }}$
Pecuniary externalities have regained the interest of researchers as they seek policy interventions and regulations to remedy externality-induced distortions, e.g., balance sheet effects, amplifiers and fire sales. In this paper we go back to first principles and show how to design financial contracts and markets in such a way that ex ante competition can achieve a constrained-efficient allocation. The key as in general equilibrium theory is to extend the commodity space in such a way that bundling, exclusivity and additional markets internalize these pecuniary externalities. We devise in this paper a general waylof proceeding that covers as a general case the large variety of example-economies which differ from $\lceil$ ne another in the particular source of the constraint generating the externality. A key take away fromlour approach is that we do not need to identify and quantify some policy intervention. With the appropriate ex ante design we can let markets solve the problem.
\end{abstract}

Weerachart T. Kilenthong

Faculty of Economics, and

Research Institute for Policy Evaluation and Desig

University of the Thai Chamber of Commerce

126/1 Vibhavadee-Rangsit, Dindaeng

Bangkok 10400

Thailand

tee@riped.utcc.ac.th

Robert M. Townsend

Department of Economics, E17-230

MIT

77 Massachusetts Avenue

Cambridge, MA 02139

and NBER

rtownsen@mit.edu 


\begin{abstract}
Pecuniary externalities have regained the interest of researchers as they seek policy interventions and regulations to remedy externality-induced distortions, e.g., balance sheet effects, amplifiers and fire sales. In this paper we go back to first principles and show how to design financial contracts and markets in such a way that ex ante competition can achieve a constrained-efficient allocation. The key as in general equilibrium theory is to extend the commodity space in such a way that bundling, exclusivity and additional markets internalize these pecuniary externalities. We devise in this paper a general way of proceeding that covers as a general case the large variety of exampleeconomies which differ from one another in the particular source of the constraint generating the externality. A key take away from our approach is that we do not need to identify and quantify some policy intervention. With the appropriate ex ante design we can let markets solve the problem.
\end{abstract}

Keywords: price externalities; segregated exchanges; Walrasian equilibrium; market-based solution; collateral; exogenous incomplete markets; moral hazard with retrading; hidden information with retrading; liquidity constraints; fire sales.

\title{
1 Introduction
}

A large variety of economies can suffer from pecuniary externalities and for a variety of distinct reasons. There is long history of research into this subject, with a solid tradition right from the beginnings of general equilibrium theory. Lately, and particularly in the aftermath

of the recent financial crisis, models with pecuniary externalities have regained the interest of researchers as they seek policy interventions and regulations to remedy externality-induced distortions, e.g., balance sheet effects, amplifiers and fire sales, to name some key words. Here in this paper we go back to first principles and show how to design financial contracts and markets in such a way that ex ante competition can achieve a constrained-efficient allocation. The key as in general equilibrium theory is to extend the commodity space in such a way that bundling, exclusivity and additional markets internalize pecuniary externalities. We devise in this paper a general way of proceeding that covers as a general case the large variety of 
example-economies which differ in the particular in the source of the constraint generating the externality.

One class of example economies are those in which collateral is used to back promises. The issuer of a promise in the contract period is required to back the promise with collateral. In the spot market/trading period the issuer can either honor the promise or default, handing over the collateral. But the value of collateral is endogenous in the spot market, determined by the forces of supply and demand at that time. Maximizing agents take prices as given and do not take into account that their actions in the contract period, the promises they issue and their savings and collateral, determine ex post spot market prices. That is, there is a collateral constraint facing the issuers of promises, which has in it those spot market prices. The problem of haircuts in which collateral backing loans receives deep discounts when markets seem to suffer from illiquidity has received, rightly, much attention. See, e.g., Begalle et al. (2013); Gorton and Metrick (2012); Krishnamurthy et al. (2012). Our own first paper on collateral-constraint-induced externalities, Kilenthong and Townsend (2014b), shows how to remedy the problem, in that specific context. This is what got us started along this more general path.

Likewise, and even simpler in some respects, when security markets are incomplete for some exogenous reason, i.e. missing an equivalent set of Arrow Debreu securities, the welfare theorems fail and competitive markets do not achieve an ex ante optimal allocation, even when the comparison of competitive equilibrium allocations to those achievable by a "planner" limits the planner to the same set of limited securities. Here spot market prices can move with initial security positions, something the planner can take into account, but in competitive markets the consequent wealth effects cannot be covered due to missing markets. See, e.g., Geanakoplos and Polemarchakis (1986). Pareto improving taxation has been proposed as a remedy ${ }^{1}$ (see, e.g., Geanakoplos and Polemarchakis, 2008; Greenwald and Stiglitz, 1986; Herings and Polemarchakis, 2005).

Our general framework encompasses economies with information problems and retrading in spot markets. For example in a moral hazard insurance economy the incentive to take

\footnotetext{
${ }^{1}$ We are reminded of Farhi and Werning (2013) though their externalities arises from sticky prices and a zero bound on interest rates, which are different from our general set up.
} 
appropriate action ex ante is induced by vectors of consumption rewards ex post. But if retrading of goods is allowed, as in ex post spot markets, this can undercut ex ante incentives. Indeed this is raised as a criticism of the realism of Prescott and Townsend (1984a b) who show how to apply the standard welfare theorems to many limited-information environments but who also do not allow retrading as in more typical dynamic spanning arguments. However, see Acemoglu and Simsek (2012); Kilenthong and Townsend (2011) for particular remedies. This again is one of our examples that set us on the general path.

Likewise, the well-known Diamond and Dybvig bank-run environment can, in the norun equilibrium at least, achieve an information-constrained efficient allocation. But this is undercut when retrading in a bond market is allowed, a point made forcefully in the seminal work of Jacklin (1987). Farhi et al. (2009) use this environment to argue for portfolio restrictions in the regulation of financial institutions.

As already mentioned, there is a growing literature on fire sales and amplifiers; where private agents undervalue net worth in a period of financial distress because they fail to internalize that net worth has positive spill overs on other agents. Bianchi and Mendoza (2012) study the relationship of these so-called credit externalities to financial fragility and welfare losses from balance sheet effects, for example. There is a much larger literature in the international context, e.g., Caballero and Krishnamurthy (2001); Jeanne and Korinek (2010). Lorenzoni (2008) is a seminal paper on inefficient credit booms and we feature that particular environment here. Others propose regulation of international capital flows, Korinek (2010), and taxation, Jeanne and Korinek (2010).

On the flip side, so to speak, Hart and Zingales (2113) study an economy where markets for the forward sale of labor are precluded, due to human capital considerations. Ironically, this leads to excess savings, not over borrowing; savings backs liquidity instruments used in trade when there are Wicksell absence-of-double-coincidence-of-wants in real goods. They show how fiscal policy following a large negative shock can increase ex ante welfare.

Again we can cast every one of these environments as an example-economy of a larger, generalized framework. The key is to be clear -- beyond preferences, endowments, and technology and beyond ordinary budget constraints -- is that there are extra constraints typically binding on a subset of agent types which contain market clearing price. These can 
be ex ante security prices or ex post prices, or both. Indeed the price-containing constraints when binding are the definition of pecuniary externalities. Examples are, again, collateral constraints, spot market budget constraint in incomplete markets, retrading entering into incentives to take ex ante action or announce ex post shocks truthfully, no default conditions, or the price of liquidity assets used in trade.

With this generalized set-up, we establish that there is a common way to internalize the externality, by having markets for rights to trade at the culprit equilibrium spot and/or security prices, bundled with the other traded objects. That is, agents pay a market participation fee, or receive a compensation, depending on the exchange, the targeted price pair, and rights to trade. An agent who chooses to trade in a security exchange can act as if she can trade commodities and securities with the specific prices indicated, in effect indexing the commodity/security trade by the price. Moreover, these are self-fulfilling in that security exchanges, given the composition of traders attracted to the exchange, are in an equilibrium fixed point. Importantly, agents are not allowed to trade with agents in other exchanges, that is, our remedy requires a registration/identification system and an exclusivity assumption; that is, an agent type can trade exclusively within his exchange but not with agents in other exchanges. But contemporary financial markets currently already have and utilize technologies which allow this to happen. We elaborate on this in some detail in the conclusion of our first paper Kilenthong and Townsend (2014b).

To reiterate, we create rights to trade in these security exchanges and in turn these rights are priced in competitive markets. These rights are the externality-correcting commodities 2 For example, in the collateral equilibrium model in Kilenthong and Townsend (2014b), this object is called the type-h discrepancy from the fundamental, that object which determines

\footnotetext{
${ }^{2}$ The rights to trade or the discrepancy from the fundamental is key to our solution concept. To ensure the consistent execution of each security exchange, the sum of the rights to trade or the discrepancies within the exchange must, by the definition of consistency, be zero so that the specified price that indexed ex ante contracts is the one which prevails in equilibrium. This is like a club constraint in other literature, e.g., Prescott and Townsend (2006). This solution concept with segregated security exchanges is also related to the assignment literature (e.g., Koopmans and Beckmann, 1957; Prescott and Townsend, 1984a b). Mortensen and Wright (2002) internalizes a search externality using directed search into segregated submarkets that promise different expected waiting times. See also Guerrieri, Shimer, and Wright (2010).
} 
the spot market price, and this discrepancy depends on type $\mathrm{h}$ endowments, his choice of collateral allocation, and the specific target fundamental/price. An alternative example is in Kilenthong and Townsend (2011), in which the rights to trade are implicitly embedded in the incentive comparability constraints. More generally, an agent's required rights to trade can be defined by excess demand functions for relevant commodities, which are again functions of his endowments, his choice of trades, and the specific target price.

A key take away from our approach is that we do not need to identify and quantify some policy intervention. Policy makers may accept the arguments in the literature about taxation, or portfolio restrictions, for example, and then ask how exactly to implement, i.e., what is the order of magnitude of the intervention. In contrast in our approach, we let markets determine prices for rights to trade, determined in the usual manner. There is no need for intervention. The outcome will be constrained-efficient (and indeed any constrained efficient allocation can be achieved with conventional ex ante lump-sum taxes and transfers that do not impede the operation of markets).

As mentioned at the outset, there are clear antecedents for what we are doing in the general equilibrium literature. This includes Arrow (1969)'s early suggestion to expand the commodity space to include the object creating the externality, following Meade (1952)'s early treatment of externalitie: $3^{3}$. The exclusive security exchanges we feature in this paper are founded in the tradition of the geographic assignment problem of Koopmans and Beckmann (1957), the labor problem of Sattinger (1993), the treatment of the firm as an endogenous object of McKenzie (1959, 1981), the treatment of firms and plants in general equilibrium of Hornstein and Prescott (1993), and the treatment of firms as clubs of Prescott and Townsend (2006).

The remaining of the paper proceeds as follows. Section 2 introduces key ingredients of the general model and then shows how the ingredients of the main example-economies map into the generalized framework, including a collateral economy, an exogenous incomplete markets economy, a moral hazard with retrading economy, and a liquidity constrained economy. For expositional purposes, each key ingredient of the general model is followed by

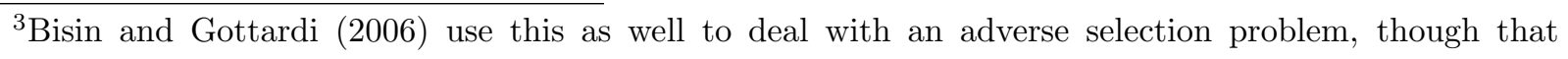
externalities is different from the pecuniary externality we feature here. 
its counterpart for each example-economies, and in the text we limit ourselves to these four to control length. Section 3 presents the competitive equilibrium with obstacles to trade and constrained optimality and establishes the existence of the externality. To save on space in the main text, and as its already covered with the notation of the general model, the competitive equilibrium and constrained optimality for each of the four example-economies are presented in Appendix A. Section 4 formally defines our market-based solution concept, the competitive equilibrium with segregated exchanges, and shows how to establish the existence and welfare theorems. The other two example-economies, including a fire sales economy and a hidden information with retrading economy are presented in entirety in Appendix B.

\section{A General Model with Price Externalities and Its Prototypical Economies}

This section formulates a general model that captures key features regarding price externalities of prototypical economies including a collateral economy (Kilenthong and Townsend, 2014b), an exogenous incomplete markets economy (Geanakoplos and Polemarchakis, 1986 , Greenwald and Stiglitz, 1986), a moral hazard with retrading economy (Kilenthong and Townsend, 2011), and a liquidity constrained economy (Hart and Zingales, 2113). Each subsection presents a key ingredient of the model along with the relevant part of each prototypical economy. More prototypical economies, namely a fire sales economy (Lorenzoni, 2008) and a hidden information with retrading economy (Diamond and Dybvig, 1983; Jacklin, 1987), are presented in Appendix B.

\subsection{Basic Ingredients: Commodity Space, Preferences, Endow- ments, and Technology}

There are $L$ commodities. These can be basic underlying commodities and also date and/or state contingent where the date and/or state are public. In order to incorporate private information problems into this framework, we also allow a subset of commodities to be contingent on recommended but unobserved actions or on reported but unobserved states. For 
actions, let $a$ be the recommended action and (with the incentive compatibility constraints in place) the actually taken action, and $a^{\prime}$ be potentially deviating action. For privately observed states, let $a$ be the reported state and (with incentive compatibility constraints in place) the actual state, and let $a^{\prime}$ be some potentially counterfactual report. Let $A \in \mathbb{R}_{+}$be the set of possible actions/states, i.e., $a, a^{\prime} \in A$.

There is a continuum of agents of measure one. The agents are divided into $H$ (ex-ante) types, each of which is indexed by $h=1,2, \cdots, H$. Each type $h$ consists of $\alpha^{h} \in[0,1]$ fraction of the population such that $\sum_{h} \alpha^{h}=1$. In addition, this model allows for ex-post diversity denoted by ex-post (either observable or unobservable) type $\omega \in \Omega$. More formally, let $\zeta^{h}(\omega)$ be the fraction of agents of type $h$ whose ex-post type is $\omega$. An ex-post type $\omega$ may depend on an observed output, an unobserved action, and/or unobserved state of nature as well.

Each agent type $h$ is endowed with an endowment $\mathbf{e}^{h} \in \mathbb{R}_{+}^{L}$. Note that $\mathbf{c}^{h}$ and $\mathbf{e}^{h}$ lie in the $L$-dimensional commodity space. The preferences of an agent of type $h$ are represented by the utility function $U^{h}\left(\mathbf{c}^{h}\right)$, where $\mathbf{c}^{h} \in \mathbb{R}^{L}$ is the consumption allocation for an agent of type $h$.

Each agent of type $h$ has an access to a production technology defined implicitly by

$$
F^{h}\left(\mathbf{y}^{h}\right) \geq 0
$$

where $\mathbf{y}^{h} \in \mathbb{R}^{L}$ is the vector of its inputs and outputs in commodity space $L$. This production technology is generally a multidimensional vector of constraints with dimension $O$, i.e., $F^{h}\left(\mathbf{y}^{h}\right) \equiv\left[F_{o}^{h}\left(\mathbf{y}^{h}\right)\right]_{o=1}^{O}$.

\subsubsection{Basic Ingredients for the Collateral Economy}

This is a two-period economy, $t=0,1$. There are a finite $S$ states of nature in the second period $t=1$, i.e., $s=1,2, \ldots, S$. Let $0<\pi_{s} \leq 1$ be the objective and commonly assessed probability of state $s$ occurring, where $\sum_{s} \pi_{s}=1$. There are two goods, called good 1 and good 2 in each period. These two goods can be traded in each date and in each state, and we refer to those markets as spot markets with good 1 as the numeraire good in every date and state. Thus, there are $L=2(1+S)$ commodities. There is no unobserved action or 
privately observed state.

Each agent of type $h=1,2, \ldots, H$ is endowed with good 1 and good $2, \mathbf{e}_{0}^{h}=\left(e_{10}^{h}, e_{20}^{h}\right)$ in the first period and $\mathbf{e}_{s}^{h}=\left(e_{1 s}^{h}, e_{2 s}^{h}\right)$, in each state $s=1, \cdots, S$. Let $\mathbf{e}^{h}=\left(\mathbf{e}_{0}^{h}, \cdots, \mathbf{e}_{S}^{h}\right)$ be the endowment profile of an agent of type $h$ over the first period and all states $s$ in the second period, respectively. There is no ex-post diversity in this economy, and therefore we simply omit all related notation.

The preferences of an agent of type $h$ are represented by the utility function $u^{h}\left(c_{1}^{h}, c_{2}^{h}\right)$, and the discounted expected utility of $h$ is defined by:

$$
U^{h}\left(\mathbf{c}^{h}\right) \equiv u^{h}\left(c_{10}^{h}, c_{20}^{h}\right)+\beta \sum_{s=1}^{S} \pi_{s} u^{h}\left(c_{1 s}^{h}, c_{2 s}^{h}\right)
$$

where $\beta$ is the discount factor.

Good 1 is consumable but cannot be stored from $t=0$ to $t=1$ (is completely perishable), while good 2 is consumable and storable. The good 2 that is stored can be collateralizable, i.e., can serve as collateral to back promises. Henceforth, good 2 and the collateral good will be used interchangeably. Each unit of good 2 stored (as input) will become $R_{s}$ units of good 2 in state $s$. As a result, the production function in our general framework can be written as follows:

$$
F_{s}^{h}\left(\mathbf{y}^{h}\right)=y_{2 s}^{h}+R_{s} y_{20}^{h}=0, \text { for } s=1, \ldots, S,
$$

where $y_{20}^{h} \in \mathbb{R}_{-}$and $y_{2 s}^{h} \in \mathbb{R}_{+}, s=1,2, \ldots, S$ are inputs and outputs, respectively. We use the standard convention under which an input must be non-positive and an output must be non-negative. This economy has $O=S$ production functions.

\subsubsection{Basic Ingredients for the Exogenous Incomplete Markets Economy}

Consider an economy with two periods, $t=0,1$. There are $S$ possible states of nature in the second period $t=1$, i.e., $s=1, \ldots, S$, each of which occurs with probability $\pi_{s}$ such that $\sum_{s} \pi_{s}=1$. There are 2 goods, labeled good 1 and good 2 , in each date and in each state. Thus, there are $L=2(1+S)$ commodities. Because the endowment profiles are the same as specified in the collateral economy discussed above, we omit the details in this section for brevity. 
The preferences of an agent of type $h$ are represented by the utility function $u^{h}\left(c_{1}^{h}, c_{2}^{h}\right)$, and the discounted expected utility of $h$ is defined by:

$$
U^{h}\left(\mathbf{c}^{h}\right) \equiv u^{h}\left(c_{10}^{h}, c_{20}^{h}\right)+\beta \sum_{s=1}^{S} \pi_{s} u^{h}\left(c_{1 s}^{h}, c_{2 s}^{h}\right),
$$

where $\beta$ is the discount factor. There is no ex-post diversity in this economy, and endowments and preferences are known ex-ante, and therefore we simply omit all related notation.

For simplicity, we assume that there is no production. Thus, $F_{o}^{h}$ can be suppressed. As a result, there would be no externalities if preferences were identically homothetic, as spot prices are determined by ratio of aggregate endowment only, which no one can influence. So we assume otherwise; that is, preferences are not identically homothetic.

\subsubsection{Basic Ingredients for the Moral Hazard with Retrading Economy}

There are two physical commodities, labeled as good 1 and good 2, in each states. These commodities can be produced using the sole input, called action, $a$. Let $A$ be the number of possible actions. As in the literature, the random production technology is given by $f(\mathbf{q} \mid a)$, which is the probability density function of the output vector of good 1 and good 2 , $\mathbf{q}=\left(q_{1}, q_{2}\right)$, conditional on an action $a$ taken by an agent. In other words, the probability that the realized output will be $\mathbf{q}$ is $f(\mathbf{q} \mid a)$ when an agent takes an action $a$. The action that an agent takes is private information. Hence, there is a moral hazard problem. There is a continuum of ex ante identical agents of mass 1, i.e., no diversity in types so trivially $\alpha^{1}=1$. For simplicity, we assume that each agent is endowed with zero units of both goods.

We will now map this moral hazard economy into our general model with securities trading. Different combinations of outputs q define (idiosyncratic) states or indexes for contracting purposes. There is no loss of generality to assume that there are a finite $Q$ states, $\mathbf{q} \in Q$. Following the mechanism design literature, an optimal consumption of the two goods under moral hazard depends on realized output $\mathbf{q}$ and recommended action $a$; that is, $c_{1}(\mathbf{q}, a)$ and $c_{2}(\mathbf{q}, a)$. Accordingly, we define commodity using both output/state $\mathbf{q}$ and recommended action $a$. In particular, for each recommended action $a$, there are $Q$ states. There are two commodities in each state. In addition, actual action $a$ itself is another commodity. Therefore, there are $L=2 Q A+1$ commodities in this model. 
Each agent is endowed with the instantaneous common utility function for the two goods and action, $u\left(c_{1}, c_{2}, a\right)$. Again, let $a$ be recommended action, and $a^{\prime}$ be taken (possibly out-of equilibrium) action. The discounted expected utility of an agent who is reported action $a$ but took action $a^{\prime}$ is define by:

$$
U(\mathbf{c})=\sum_{\mathbf{q}} \pi\left(\mathbf{q} \mid a^{\prime}\right) u\left(c_{1}(\mathbf{q}, a), c_{2}(\mathbf{q}, a), a^{\prime}\right)
$$

where $\pi(\mathbf{q} \mid a)$ denote the probability of realizing outputs $\mathbf{q}$ given action $a$ (actually taken), which satisfies the following probability constraint:

$$
\sum_{\mathbf{q}} \pi(\mathbf{q} \mid a)=1, \forall a
$$

Ex-post diversity in this model is determined by actual (ex ante) action and realized (ex post) outputs, i.e., $\omega=\left(\mathbf{q}, a^{\prime}\right)$. For generality, let $\delta\left(a^{\prime}\right)$ be the fraction of agents who took action $a^{\prime}$. Recall that the fraction of agents who realized outputs $\mathbf{q}$ conditional on taking action $a^{\prime}$ is $f\left(\mathbf{q} \mid a^{\prime}\right)$. As a result, the fractions of agents of ex-post type $\left(\mathbf{q}, a^{\prime}\right)$ is $\zeta^{1}\left(\mathbf{q}, a^{\prime}\right)=f\left(\mathbf{q} \mid a^{\prime}\right) \delta\left(a^{\prime}\right)$.

As in the literature, the probability distribution across outputs/states depend on agent's choice of action $a$. This dependency is modeled as a general production function $F$ whose input is actual action $a$ and outputs are $\mathbf{q}$ :

$$
F(\mathbf{q}, a)=f(\mathbf{q} \mid a)-\pi(\mathbf{q} \mid a)=0, \forall \mathbf{q}, a
$$

In words, different actions will lead to different probability distributions. There are, as in (7), $O=Q A$ production functions. Combining these production technologies with the probability conditions (6) leads to the standard probability constraints of production function $f(\mathbf{q} \mid a)$ :

$$
\sum_{\mathbf{q}} \pi(\mathbf{q} \mid a)=1 \Rightarrow \sum_{\mathbf{q}} f(\mathbf{q} \mid a)=1, \forall a
$$

\subsubsection{Basic Ingredients for the Liquidity Constrained Economy}

Consider an economy with four periods, $t=0,1,2,3$. There are two types of agents, called "doctors" and "builders", each of which consists of $\alpha^{h}>0$ for all $h=b, d$ fraction of the

population with $\sum_{h=b, d} \alpha^{h}=1$. Each agent $h=b, d$ is endowed with $e^{h}=e$ units of wheat 
at period $t=0$. This is a simplified and deterministic version of Hart and Zingales (2113) in which we assume that the doctors will buy building services in period $t=1$ first, and the builders will buy doctor services later in period $t=2$. As in the collateral model in section 2.1.1, there is no unobserved action or privately observed state, and therefore we simply omit all related notation.

There are two commodities in period $t=0$, wheat $w_{0}^{h}$, and storage $f_{0}^{h}$, where the latter is formally defined below. There are three commodities in period $t=1$, storage $f_{1}^{h}$, building services $b^{d}$ and labor supply of the doctors $l^{d}$. Similarly, there are three commodities in period $t=2$, storage $f_{2}^{h}$, doctor services $d^{b}$, and labor supply of the builders $l^{b}$. There is one commodity, wheat $w_{3}^{h}$, in the last period $t=3$. Therefore, there are $L=9$ commodities in this model.

The preferences of doctors and builders are represented by

$$
\begin{aligned}
& U^{d}(\mathbf{c})=u^{d}\left(w^{h}, d^{h}, b^{h}, l^{h}\right)=w_{3}^{h}+b^{h}-\frac{\left(l^{h}\right)^{2}}{2} \\
& U^{b}(\mathbf{c})=u^{b}\left(w^{b}, d^{b}, b^{b}, l^{b}\right)=w_{3}^{b}+d^{b}-\frac{\left(l^{b}\right)^{2}}{2}
\end{aligned}
$$

respectively. Note that doctors do not consume doctor services, and vice versa for builders. We can write the utility function in a more general from as follows:

$$
U^{h}(\mathbf{c})=u^{h}\left(w^{h}, d^{h}, b^{h}, l^{h}\right)=w_{3}^{h}+\delta_{b}^{h} b^{h}+\left(1-\delta_{d}^{h}\right) d^{h}-\frac{\left(l^{h}\right)^{2}}{2}
$$

where $\delta_{b}^{h}=1$ if $h \neq b$, and zero otherwise.

There are two technologies or assets available in period $t=0$. First, the collateralizeable asset is a storage technology, whose return from $t=0$ to $t=3$ is 1 unit of wheat, i.e., saving one unit of wheat in the first period $t=0$ will return 1 unit of wheat in the last period $t=3$. In addition, the claim on the output of this technology is transferable, and therefore can be used as private money (or collateral) during periods $t=1$ and $t=2$. The second asset is an investment project, whose return from $t=0$ to $t=3$ is $\bar{R}>1$ units of wheat. However, this asset cannot be used as collateral. For simplicity, we consider only a deterministic return case here. Let $f_{0}^{h}$ be the amount of wheat stored by an agent type $h=b, d$, and accordingly, the agent type $h$ invests $e-f_{0}^{h}$ units of wheat in the investment project. 
The production technologies are irreversible; that is, their outputs will be realized in the last period $t=3$ only. The production function of the storage technology (denoted by subscript "s") for an agent type $h$ is defined as follows:

$$
F_{s}^{h}\left(f_{2}^{h}, y_{31}^{h}\right)=y_{s 3}^{h}-f_{2}^{h}=0, \forall h=b, d
$$

where $f_{2}^{h}$ is the number of claims on the storage technology held by the agent type $h$ at the end of period $t=2$, and $y_{s 3}^{h}$ is the output in unit of wheat in period $t=3$ received by the agent type $h$ from the storage technology. Similarly, the production function for investment project (denoted by subscript "i") is defined by

$$
F_{i}^{h}\left(e-f_{0}^{h}, y_{i 3}^{h}\right)=y_{i 3}^{h}-\bar{R}\left(e-f_{0}^{h}\right)=0, \forall h,
$$

where $f_{0}^{h}$ is the amount of wheat stored by an agent type $h$ in period $t=0$, and $y_{i 3}^{h}$ is the output in unit of wheat in period $t=3$ received by the agent type $h$ from the investment technology .

In addition, the builders and the doctors produce building and doctor services (denoted by subscript "o"), respectively, using the following simple linear technologies:

$$
F_{o}^{h}\left(y_{h}^{h}, l^{h}\right)=y_{h}^{h}-l^{h}=0, \forall h=b, d
$$

which use labor as the only input. For notational convenience, we also set

$$
F_{0}^{h}\left(y_{-h}^{h}\right)=y_{-h}^{h}=0, \forall h=b, d,
$$

where $y_{-h}^{h}=y_{b}^{d}$, $y_{d}^{b}$ denote building services produced by doctors and vice versa. To sum up, there are $O=4$ production functions.

\subsection{Market Structure: Security and Spot Markets}

There are $J$ securities. Let $\theta_{j}^{h} \in \mathbb{R}$ denote the amount of security $j$ acquired (negative if sold) by an agent of type $h$, and $D_{j}=\left[D_{j l} l_{l=1}^{L} \in \mathbb{R}_{+}^{L}\right.$ denote its payoff vector. Note securities have payoffs of goods in the $L$-dimensional space of underlying commodities. Notationally, let $D=\left[D_{j}\right]_{j=1}^{J}$ be the payoff matrix of all securities. Let $\mathbf{P} \in \mathbb{R}_{+}^{J}$ be the price vector of all securities, that is, $P_{j} \geq 0$ for $j=1, \ldots, J$. 
In addition, agents can trade in each of $S$ restricted (ex-post spot) markets of subsets of commodities. Let $L^{s}$ be the subset of commodities that can be traded in an $s$ restricted (spot) markets such that $\cup_{s=1}^{S} L^{s} \subset L$. Note that ex-post trades are in proper subsets of commodity space $L$ as some dates or states are by then realized or known. With abuse of notation, let $L^{s}$ denote the number of commodities in $L^{s}$. These markets are assumed to be mutually exclusive, i.e., $L^{s} \cap L^{s^{\prime}}=\emptyset$ for any $s \neq s^{\prime}$.

Let $\tau^{h}$ denote the set of trades in these markets with $\tau_{\ell s}^{h}(\omega)$ denoting the amount of the $\ell^{\text {th }}$ good in market $L^{s}$ acquired (negative if surrendered) by an agent of ex-ante type $h$ and ex-post type $\omega$. Note again that these spot trades $\tau_{\ell s}^{h}(\omega)$ are restricted to be traded with commodities in $L^{s}$ only. Let $\tilde{\mathbf{p}}_{s} \equiv\left[\tilde{p}_{\ell s}\right]_{\ell \in L^{s}} \in \mathbb{R}_{+}^{L^{s}}$ be the price vector of commodities in $L^{s}$.

The relationship between consumption, endowments, securities, spot trades, and outputs for an agent of type $h$ is defined implicitly by

$$
g^{h}\left(\mathbf{c}^{h}, \mathbf{e}^{h}, \theta^{h}, \tau^{h}, \mathbf{y}^{h}\right)=0 .
$$

These will be obvious identities or accounting formulas in the examples which follow. This condition is generally multidimensional vector with dimension $N$, i.e.,

$$
g^{h} \equiv\left(g_{n}^{h}\left(\mathbf{c}^{h}, \mathbf{e}^{h}, \theta^{h}, \tau^{h}, \mathbf{y}^{h}\right)\right)_{n=1}^{N} .
$$

\subsubsection{Market Structure for the Collateral Economy}

Let $\theta_{k s}^{h}$ denote securities paying in good $k=1,2$ in state $s$ or net transfers of good $k=1,2$ in state $s$ acquired by an agent type $h$. If this is negative, it is a promise to pay. Also $\theta_{k 0}^{h}$ is spot purchase of good $k$ at $t=0$ but for convenience we refer to this as a security trade. Thus there are $J=2(1+S)$ securities. Let $P_{\ell 0}$ and $P_{\ell s}$ denote the security (spot) price of $\operatorname{good} \ell$ at period $t=0$ and the price of a security paying in $\operatorname{good} \ell$ in state $s$, respectively. We take good $\ell=1$ as the numeraire.

Let $\tau_{k s}^{h}$ denote spot trade amount of good $k=1,2$ in spot markets $L^{s}$ in state $s$ acquired by an agent of ex-ante type $h$. With abuse of notation, let $\tau_{k 0}^{h}$ denote spot trade amount of good $k$ in spot markets $L^{0}$ in period $t=0$ acquired by an agent of ex-ante type $h$. Each spot market has two commodities, namely good 1 and good 2, i.e., $L^{s}=2$ for all $s=0,1, \ldots, S$. There are $S+1$ spot markets here. We set the spot-market-clearing price of good 1 equal 
to one (the numeraire good), and let $\tilde{p}_{s}$ denote the spot-market-clearing price of good 2 in each spot market $L^{s}$.

The consumption-relationship constraints in this case are defined as follows:

$$
g_{k s}^{h}\left(\mathbf{c}^{h}, \mathbf{e}^{h}, \theta^{h}, \tau, \mathbf{y}^{h}\right)=e_{k s}^{h}+y_{k s}^{h}+\theta_{k s}^{h}+\tau_{k s}^{h}-c_{k s}^{h}=0, \text { for } k=1,2 ; s=0,1, \ldots, S,
$$

where we set $y_{10}^{h}=0$ and $y_{1 s}^{h}=0$ to represent the fact that good 1 cannot be stored. There are $N=2(1+S)$ consumption-relationship constraints. As proved in Kilenthong and Townsend (2014b), with complete collateralized contracts, there is no need for restricted/spot trades $\tau$ in this case. All trades can be accomplished in ex-ante security markets. As a result, the consumption-relationship constraints can be rewritten as follows:

$$
g_{k s}^{h}\left(\mathbf{c}^{h}, \mathbf{e}^{h}, \theta^{h}, \mathbf{y}^{h}\right)=e_{k s}^{h}+y_{k s}^{h}+\theta_{k s}^{h}-c_{k s}^{h}=0, \text { for } k=1,2 ; s=0,1, \ldots, S
$$

Nevertheless, we can define what the ex-post spot price $\tilde{p}_{s}$ would be that would clear these markets (without active trade).

\subsubsection{Market Structure for the Exogenous Incomplete Markets Economy}

There are $J<S$ securities available for purchase or sell in the first period $t=0$. Let $D=\left[D_{j s}\right]$ be the payoff matrix of those assets where $D_{j s}$ be the payoff of asset $j$ in unit of good 1 (the numeraire good) in state $s$ in the second period $t=1, s=1,2, \ldots, S$. Let $\theta_{j}^{h}$ denote the amount of the $j^{t h}$ security acquired by an agent of type $h$ at $t=0$, and $P_{j}$ denote the price of security $j$. An exogenous incomplete markets assumption specifies that $D$ is not full rank; that is again, $J<S$. This is crucial.

Let $\tau_{k s}^{h}$ denote spot trade amount of good $k=1,2$ in spot markets $L^{s}$ in state $s$ acquired by an agent of ex-ante type $h$. With abuse of notation, let $\tau_{k 0}^{h}$ denote spot trade amount of good $k=1,2$ in spot markets $L^{0}$ in period $t=0$ acquired by an agent of ex-ante type $h$. Each spot market has two commodities, namely good 1 and good 2 , i.e., $L^{s}=2$ for all $s=0,1, \ldots, S$. There are $S+1$ spot markets here. We set the spot-market-clearing price of good 1 equal to one (the numeraire good), and let $p_{0}$ and $\tilde{p}_{s}$ denote the spot-market-clearing price of good 2 in spot market $L^{0}$ in period $t=0$, and the spot-market-clearing price of good 2 in spot market $L^{s}$ at state $s$ in period $t=1$, respectively. 
The consumption-relationship functions in the first period $t=0$ is defined as follows:

$$
g_{k}^{h}\left(\mathbf{c}^{h}, \mathbf{e}^{h}, \theta^{h}\right)=e_{k 0}^{h}+\tau_{k 0}^{h}-c_{k 0}^{h}=0, \text { for } k=1,2 .
$$

The consumption-relationship function for good 1 and good 2, respectively, in the state $s$ in the second period is defined as follows:

$$
\begin{aligned}
& g_{1+2 s}^{h}\left(\mathbf{c}^{h}, \mathbf{e}^{h}, \theta^{h}, \tau^{h}\right)=e_{1 s}^{h}+\sum_{j} D_{j s} \theta_{j}^{h}+\tau_{1 s}^{h}-c_{1 s}^{h}=0, \text { for } s=1, \ldots, S, \\
& g_{2+2 s}^{h}\left(\mathbf{c}^{h}, \mathbf{e}^{h}, \theta^{h}, \tau^{h}\right)=e_{2 s}^{h}+\tau_{2 s}^{h}-c_{2 s}^{h}=0, \text { for } s=1, \ldots, S .
\end{aligned}
$$

Note here there will be active spot market trades $\tau$ to support the equilibrium allocation. To sum up, there are $N=2(1+S)$ consumption-relationship constraints.

\subsubsection{Market Structure the Moral Hazard with Retrading Economy}

To be consistent with the general model, one can imagine that there are state-contingent securities paying in good $k=1,2$ when state/output is $\mathbf{q}$ and the recommended action is $a$, namely $\theta_{k}(\mathbf{q}, a)$. That is, security $j$ is indexed by $\mathbf{q}, k$, and $a$. Even though there are $J=2 Q A$ securities available to trade, each agent can trade only $2 Q$ securities depending on his recommended action $a$ only. In particular, an agent recommended action $a$ will be able to trade only securities $\theta_{a} \equiv\left[\theta_{k}(\mathbf{q}, a)\right]_{k, \mathbf{q}}$. Let $P_{k}(\mathbf{q}, a)$ denote the price of a security paying in good $k$ conditional on output $\mathbf{q}$ and recommended action $a$. Recall that actual action $a^{\prime}=a$ is an input of the production technology, and there is no loss of generality to assume that it is non-tradable. Therefore, there is no price for that commodity action. Note also that as in the literature, these equilibrium securities prices are fair prices.

There is the possibility of retrade in ex post spot markets. One can think of two subperiods: the first with the application of inputs, securities, and production; the second for output and possible retrading with final consumption. Without aggregate uncertainty, there is only one set of spot markets $(S=1)$ for good 1 and good $2\left(L^{s}=2\right)$, in which everyone participates. Let $\tau_{k}(\mathbf{q}, a)$ be spot trade of an agent of ex-post type $(\mathbf{q}, a)$ when $a$ is both the recommended and taken action. We set the spot-market-clearing price of good 1 equal to one (the numeraire good), and let $\tilde{p}$ denote the spot-market-clearing price of good 2, which depends on agents' action $a$ (recommended and taken) and securities $\theta_{a}=\left[\theta_{k}(\mathbf{q}, a)\right]_{k, \mathbf{q}}$ as a 
function of recommended action $a$ (as if the markets can be partitioned by action $a$ ); that is, $\tilde{p}=\tilde{p}\left(\theta_{a}, a\right)$.

As in Kilenthong and Townsend (2011) and the collateral example in Section 2.2.1, the spot markets are redundant (with complete contracts), however. Anything that can be done with spot markets can be done without them with altered security holdings. Therefore, we can omit spot trades, henceforth, though there is still an implicit shadow spot price. The consumption-relationship in this case is defined as follows:

$$
g_{k \mathbf{q} a}=q_{k}+\theta_{k}(\mathbf{q}, a)-c_{k}(\mathbf{q}, a)=0, \forall \mathbf{q}, a ; k=1,2
$$

There are $N=2 Q A$ consumption-relationship constraints.

\subsubsection{Market Structure the Liquidity Constrained Economy}

To be consistent with the general model, there is no security in this model; that is, $J=0$. All trades occur in the spot markets. There are 2 sets of spot markets in period $t=1$ and $t=2$; that is, $S=2$. Agents can trade storage claim $\tau_{f 1}^{h}$ and building services $\tau_{b}^{h}$ in the spot markets in period $t=1$ at price $\tilde{p}_{b}$; that is, there are two commodities in the spot markets in period $t=1\left(L^{1}=2\right)$. Similarly, agents can trade storage claim $\tau_{f 2}^{h}$ and doctor services $\tau_{d}^{h}$ in the spot markets in period $t=2$ at price $\tilde{p}_{d}$; that is, there are two commodities in the spot markets in period $t=2\left(L^{2}=2\right)$.

The consumption-relationship constraints are as follows:

$$
\begin{aligned}
g_{b}^{h}\left(b^{h}, y_{b}^{h}, \tau_{b}^{h}\right) & =b^{h}-\left(y_{b}^{h}+\tau_{b}^{h}\right)=0, \forall h, \\
g_{d}^{h}\left(d^{h}, y_{d}^{h}, \tau_{d}^{h}\right) & =d^{h}-\left(y_{d}^{h}+\tau_{d}^{h}\right)=0, \forall h, \\
g_{w}^{h}\left(w^{h}, y_{i 3}^{h}, y_{s 3}^{h}\right) & =w_{3}^{h}-y_{i 3}^{h}-y_{s 3}^{h}=0, \forall h, \\
g_{f t}^{h}\left(f_{t}^{h}, f_{t-1}^{h}, \tau_{f t}^{h}\right) & =f_{t}^{h}-f_{t-1}^{h}-\tau_{f t}^{h}=0, \forall h ; t=1,2 .
\end{aligned}
$$

To sum up, there are $N=6$ consumption-relationship constraints.

\subsection{Trade Frictions: Obstacle-to-Trade Constraints}

Price externalities in this model come from the fact that agents face obstacles to trade that depend on prices. These obstacles are formulated as constraints and are called obstacle- 
to-trade constraints. Each set of obstacle-to-trade constraints depends on the prices of a particular subset of securities denoted $\tilde{\mathbf{P}}^{i}$ or the prices of a particular subset of commodities $\tilde{\mathbf{p}}^{i}$, or both. Let $J^{i} \leq J$ be the dimensions of $\tilde{\mathbf{P}}^{i}$, and $L^{i} \leq L$ be the dimensions of $\tilde{\mathbf{p}}^{i}$. There are $I$ sets of obstacle-to-trade constraints 4 . That is, there are $I$ sets of prices $\left(\tilde{\mathbf{p}}^{i}, \tilde{\mathbf{P}}^{i}\right)$ relevant to obstacle-to-trade constraints. These obstacle-to-trade constraints could be in the form of collateral constraints, retrading in exogenous incomplete-market constraints, incentive compatibility constraints under moral hazard with retrading, incentive compatibility constraints under hidden information with retrading, liquidity constraints, and no-default constraints.

Each set of obstacle-to-trade constraints $C_{i}^{h} \equiv\left[C_{i, a, a^{\prime}}^{h}\right]_{a, a^{\prime}=1}^{A}$ for an agent of type $h$ consists of $A^{2}$ obstacle-to-trade constraints, each of which depends on the same set of prices $\left(\tilde{\mathbf{p}}^{i}, \tilde{\mathbf{P}}^{i}\right)$. These put restriction on securities, spot trades, and output and are defined as follows:

$$
C_{i, a, a^{\prime}}^{h}\left(\mathbf{c}^{h}, \theta^{h}, \tau^{h}, \mathbf{y}^{h}, \tilde{\mathbf{p}}^{i}, \tilde{\mathbf{P}}^{i}\right) \geq 0, \text { for } i=1, \ldots, I ; a \in A ; a^{\prime} \in A
$$

The total number of obstacle-to-trade constraints is $M=I A^{2}$. Note that an action as in a moral hazard model, or privately observed state indexes the commodities, and therefore is included in $\mathbf{c}^{h}$.

The dependency on market-clearing prices of these obstacle-to-trade constraints is the source of price externalities in this paper. Most of the literature focuses only on the dependency on the restricted/spot prices. This paper explicitly puts security prices into the constraints in order to emphasize that price externalities could arise even when we shut down the spot markets. In other words, the spot markets/prices are not fundamental to the externality problem. It is an obstacle to trade itself, which can not be removed, that is key to the problem. As shown in the collateral economy below, one can get rid of the spot markets there since they are redundant. The collateral constraints (the need to back promises by collateral) then depend on security prices only, but the price externality still occurs.

\footnotetext{
${ }^{4}$ There is no loss of generality in setting the dimensionality of the obstacle-to-trade constraints identical for all agent's types. Consider a model where different types face different numbers of obstacle-to-trade constraints. Let $I^{h}$ be the number of obstacle-to-trade constraints faced by an agent of type $h$. Set $I=$ $\max _{h} I^{h}$. For an agent of type $\tilde{h}$ whose $I^{\tilde{h}}<I$, we then define $C_{i}^{\tilde{h}}=\emptyset$ for $I^{\tilde{h}}<i \leq I$.
} 


\subsubsection{Trade Frictions for the Collateral Economy}

As in Kilenthong and Townsend (2014b), the collateral constraints or obstacle-to-trade constraints state that the value of collateral $y_{2 s}^{h}$ must weakly exceed value of promises to pay $\left(\theta_{1 s}^{h}, \theta_{2 s}^{h}\right)$ :

$$
\tilde{p}_{s} y_{2 s}^{h} \geq \tilde{p}_{s}\left(-\theta_{2 s}^{h}\right)+\left(-\theta_{1 s}^{h}\right), \text { for } s=1, \ldots, S,
$$

which can be rewritten as follow:

$$
\tilde{p}_{s}\left(y_{2 s}^{h}+\theta_{2 s}^{h}\right)+\theta_{1 s}^{h} \geq 0, \text { for } s=1, \ldots, S,
$$

where again $\tilde{p}_{s}$ is the spot price of good 2 in units of good 1 in state $s$.

But as mentioned earlier, these collateral constraints can be rewritten in terms of security prices as following:

$$
C_{s}^{h}\left(\theta^{h}, \mathbf{y}^{h}, \tilde{\mathbf{P}}_{s}\right)=P_{2 s}\left(y_{2 s}^{h}+\theta_{2 s}^{h}\right)+P_{1 s} \theta_{1 s}^{h} \geq 0, \text { for } s=1, \ldots, S,
$$

which results from the fact that, with complete state contingent contracts at $t=0$ and

the possibility of retrading, the spot price ratio $\tilde{p}_{s}$ equals to the ratio of security prices $\frac{P_{2 s}}{P_{1 s}}$. This formulation emphasizes that we can shut down the spot markets, but the collateral constraints still depend on security prices, which still generate externalities. In other words, the spot markets/prices are not fundamental to the externality problem. It is an obstacle to trade itself, which can not be removed, that is key to the problem.

Each agent of type $h$ faces $I=S$ sets of obstacle-to-trade constraints, each of which contains only one constraint, i.e., technically $A=1$. Therefore, there are $M=S$ obstacleto-trade constraints in total.

\subsubsection{Trade Frictions for the Exogenous Incomplete Markets Economy}

The obstacle-to-trade or spot-budget constraint for an agent of type $h$ in each state $s$ is simply the budget constraint in that state:

$$
C_{s}^{h}\left(\tau_{s}^{h}, \tilde{p}_{s}\right)=\tau_{1 s}^{h}+\tilde{p}_{s} \tau_{2 s}^{h}=0, \text { for } s=1, \ldots, S,
$$

Note that the spot price $\tilde{p}_{s}$ is determined by pre-trade position of endowments and securities where endowments are exogenous but securities are endogenous. 
Each agent of type $h$ faces $I=S$ sets of obstacle-to-trade constraints, each of which contains only one constraint, i.e., $A=1$. Therefore, there are $M=S$ obstacle-to-trade constraints in total.

\subsubsection{Trade Frictions for the Moral Hazard with Retrading Economy}

The possibility of retrade in ex post spot markets creates obstacle to trade in this model. With the possibility of retrade, the ex-post utility maximization problem of an agent who was recommended action $a$ receiving compensation $\left(c_{1}(\mathbf{q}, a), c_{2}(\mathbf{q}, a)\right)$, but took action $a^{\prime}$ when the spot market price is $\tilde{p}$ is as follows:

$$
v\left(c_{1}(\mathbf{q}, a), c_{2}(\mathbf{q}, a), a^{\prime}, \tilde{p}\right)=\max _{\tau_{1}, \tau_{2}} u\left(c_{1}(\mathbf{q}, a)+\tau_{1}, c_{2}(\mathbf{q}, a)+\tau_{2}, a^{\prime}\right)
$$

subject to the budget constraint:

$$
\tau_{1}+\tilde{p} \tau_{2}=0,
$$

taking spot-market-clearing price $\tilde{p}$ as given.

As in Kilenthong and Townsend (2011), the possibility of retrade in ex post spot markets and the moral hazard problem imply that the incentive compatibility constraints (IC) are as following: $\forall a, a^{\prime}$,

$$
\begin{aligned}
C_{1, a, a^{\prime}}(\mathbf{c}, \tilde{p}) & =\sum_{\mathbf{q}} u\left(c_{1}(\mathbf{q}, a), c_{2}(\mathbf{q}, a), a\right) f(\mathbf{q} \mid a) \\
& -\sum_{\mathbf{q}} v\left(c_{1}(\mathbf{q}, a), c_{2}(\mathbf{q}, a), a^{\prime}, \tilde{p}\right) f\left(\mathbf{q} \mid a^{\prime}\right) \geq 0,
\end{aligned}
$$

Here the agent takes the recommended action $a$ and so $a=a^{\prime}$. There is only one set of obstacle-to-trade constraints, $I=1$, and there are $A^{2}$ constraints for this one $i$. Therefore, there are $M=A^{2}$ incentive compatibility constraints in total.

\subsubsection{Trade Frictions for the Liquidity Constrained Economy}

The obstacle-to-trade or spot market constraints for an agent type $h=b, d$ in period $t$ are as follows:

$$
\begin{aligned}
& C_{1}^{h}\left(\tau_{f 1}^{h}, \tau_{b}^{h}, \tilde{p}_{b}\right)=\tau_{f 1}^{h}+\tilde{p}_{b} \tau_{b}^{h}=0, \forall h=b, d, \\
& C_{2}^{h}\left(\tau_{f 2}^{h}, \tau_{d}^{h}, \tilde{p}_{d}\right)=\tau_{f 2}^{h}+\tilde{p}_{d} \tau_{d}^{h}=0, \forall h=b, d,
\end{aligned}
$$


where $\tilde{p}_{b}$ and $\tilde{p}_{d}$ are the spot-market-clearing prices of building and doctor services in period $t=1$ and $t=2$, respectively; that is, $\tilde{p}_{b}$ is such that $\sum_{h=b, d} \alpha^{h} \tau_{b}^{h}=0$, and vice versa. Note that the spot price $\tilde{p}_{b}$ and $\tilde{p}_{d}$ are determined by storage positions of all agents which are endogenous. Each agent of type $h$ faces $I=2$ sets of obstacle-to-trade constraints, each of which contains only one constraint, i.e., $A=1$. Therefore, there are $M=2$ obstacle-to-trade constraints in total.

\section{Price Externalities}

There is an externality because the consumption feasibility set of an agent type $h$ depends on other agents' choices through prices. To reiterate, this dependency results from the obstacleto-trade constraints. If there were no obstacle-to-trade constraints, then each agent's consumption feasibility set would be independent of other agents' choices (and therefore there would be no externality). Intuitively, an infinitesimal agent has no influence on aggregate resource allocation, which determines prices. On the other hand, a constrained planner knows she can influence prices through agents' choices collectively. The asymmetry between the influence of the planner versus agents generates an inefficiency when any one of obstacle-totrade constraints, which contain prices, is binding for any agent type. We now present the formal statement below. For simplicity, we focus on identical allocations for each type.

\subsection{Competitive Equilibrium with Obstacles to Trade}

An agent of type $h$ maximizes his utility:

\section{Program 1.}

$$
\max _{\mathbf{c}^{h}, \theta^{h}, \tau^{h}, \mathbf{y}^{h}} U^{h}\left(\mathbf{c}^{h}\right)
$$


subject to the budget, consumption-relationship, technology, and the obstacle-to-trade constraints, respectively:

$$
\begin{aligned}
\sum_{j=1}^{J} P_{j} \theta_{j}^{h} & \leq 0, \\
\sum_{\ell=1}^{L^{s}} \tilde{p}_{\ell s} \tau_{\ell s}^{h}(\omega) & \leq 0, \forall s, \omega, \\
g_{n}^{h}\left(\mathbf{c}^{h}, \mathbf{e}^{h}, \theta^{h}, \tau^{h}, \mathbf{y}^{h}\right) & =0, \forall n, \\
F_{o}^{h}\left(\mathbf{y}^{h}\right) & =0, \forall o, \\
C_{i, a, a^{\prime}}^{h}\left(\mathbf{c}^{h}, \theta^{h}, \tau^{h}, \mathbf{y}^{h}, \tilde{\mathbf{p}}^{i}, \tilde{\mathbf{P}}^{i}\right) & \geq 0, \forall i, a, a^{\prime},
\end{aligned}
$$

taking prices $\tilde{\mathbf{p}}^{i}, \tilde{\mathbf{P}}^{i}$, and $\mathbf{P}$ as given.

In order to deal with ex post diversity in private information problems, we define some participation mechanism. Let $\xi_{j}^{h}$, called eligibility weight, denote the mass of agents of type $h$ who are eligible to trade security $j$, and hence $\xi_{j}=\sum_{h} \alpha^{h} \xi_{j}^{h}$ be the total mass of agents of all types who are eligible to trade security $j$, adding up over ex-ante types. Note that $\xi_{j}^{h}$ can depend on observable actions or unobserved states in $A$.

In addition, we also need to introduce financial intermediaries below in order to generally represent economies with collateral requirements, incomplete markets, private information, liquidity constraints, and fire sales in the same general framework. It is worthy of emphasis that the existence of financial intermediaries is not the cause of price externalities in this model. Intermediaries simply bundle commodities and facilitate trade.

The representative financial intermediary supplies securities $\psi=\left(\psi_{j}\right)_{j}, j=1,2, \ldots, J$ (per unit of eligible agents) to maximize its profit taking prices as given. The profit maximization problem of the representative financial intermediary is as follows:

$$
\max _{\psi} \sum_{j=1}^{J} P_{j} \xi_{j} \psi_{j}
$$

subject to feasibility constraints (potentially multi-dimensional)

$$
\sum_{j=1}^{J} \Psi_{m j} \xi_{j} \psi_{j}=0, \text { for } m=1, \ldots, M
$$


taking prices $\mathbf{P}$ as given, where $\Psi=\left[\Psi_{m j}\right]_{m, j}$ is the matrix of security weights for the $j^{\text {th }}$ security in the $m^{\text {th }}$ feasibility constraint. Note there are constant returns to scale so we act as if there will be one price-taking intermediary.

The market clearing conditions for securities are as follows:

$$
\sum_{h} \alpha^{h} \theta_{j}^{h}=\psi_{j}, \forall j
$$

These conditions simply state that the net demand for securities equates that supplied by the intermediary sector. Note that combining the feasibility constraints (45) and the market clearing constraints for securities (46) gives the resource constraints (49), written below.

The market clearing conditions for every spot market $L^{s}$ are as follows:

$$
\sum_{h} \sum_{\omega} \alpha^{h} \zeta^{h}(\omega) \tau_{\ell s}^{h}(\omega)=0, \forall \ell \in L^{s} ; s \in S
$$

The market clearing constraints for restricted/spot trades (47) ensure that spot prices $\tilde{p}^{i}$ are consistent. That is, spot prices $\tilde{p}^{i}$ are such that (47) is satisfied and so each restricted/spot market clears.

Definition 1. A competitive equilibrium with obstacles to trade is a specification of allocation $\left(\mathbf{c}^{h}, \theta^{h}, \tau^{h}, \mathbf{y}^{h}\right)$ for households and $\psi$ for intermediaries, and prices $\left(\tilde{\mathbf{p}}^{i}, \tilde{\mathbf{P}}^{i}, \mathbf{P}\right)$ such that

(i) for each type $h,\left(\mathbf{c}^{h}, \theta^{h}, \tau^{h}, \mathbf{y}^{h}\right)$ solves 38 subject to $\left.39-43\right)$, taking prices $\left(\tilde{\mathbf{p}}^{i}, \tilde{\mathbf{P}}^{i}, \mathbf{P}\right)$ as given;

(ii) for the financial intermediary, $\psi$ solves 44 subject to 45 , taking prices $\mathbf{P}$ as given;

(iii) markets for securities and for spot trades clear; 46 and 47 hold.

For expositional simplicity and without loss of generality, we consider only equal-treatment (for each type) and interior solutions, and assume that all functions are differentiable. A necessary optimal condition for a competitive equilibrium allocation with respect to $y_{\ell}^{h}$ is

$$
\sum_{n=1}^{N} \gamma_{g_{n}}^{h} \frac{\partial g_{n}^{h}}{\partial y_{\ell}^{h}}+\sum_{o=1}^{O} \gamma_{F_{o}}^{h} \frac{\partial F_{o}^{h}}{\partial y_{\ell}^{h}}+\sum_{i=1}^{I} \sum_{a=1}^{A} \sum_{a^{\prime}=1}^{A} \gamma_{C_{i, a, a^{\prime}}}^{h} \frac{\partial C_{i, a, a^{\prime}}^{h}}{\partial y_{\ell}^{h}}=0, \forall h, \ell
$$


where $\gamma_{g_{n}}^{h}, \gamma_{F_{o}}^{h}$ and $\gamma_{C_{i, a, a^{\prime}}}^{h}$ are the Lagrange multipliers with respect to the $n^{\text {th }}$ consumptionrelationship constraint, 41); the $o^{\text {th }}$ technology constraint of agent $h$, 42); and obstacle-totrade constraint $\left(i, a, a^{\prime}\right)$ of an agent of type $h$, (43), respectively.

\subsection{Constrained Optimality}

Attainable allocations are those that can be achieved by exchanges of commodities and by production subject to both resource constraints and obstacle-to-trade constraints. In addition, it also requires that the allocation of relevant commodities (under the $i^{\text {th }}$ obstacleto-trade constraints) must lead to market-clearing prices $\tilde{\mathbf{p}}^{i}$ and $\tilde{\mathbf{P}}^{i}$. More formally, this consistency condition can be written as follows $\tilde{\mathbf{p}}^{i}=\tilde{\mathbf{p}}^{i}(\mathbf{c}, \theta, \mathbf{y}, \mathbf{e})$ and $\tilde{\mathbf{P}}^{i}=\tilde{\mathbf{P}}^{i}(\mathbf{c}, \theta, \mathbf{y}, \mathbf{e})$ where $(\mathbf{c}, \theta, \mathbf{y}, \mathbf{e}) \equiv\left(\mathbf{c}^{h}, \theta^{h}, \mathbf{y}^{h}, \mathbf{e}^{h}\right)_{h}$.

Definition 2. An allocation $(\mathbf{c}, \theta, \tau, \mathbf{y})$ is attainable if

(i) it satisfies the resource constraints:

$$
\begin{aligned}
\sum_{j=1}^{J} \Psi_{m j} \xi_{j} \sum_{h} \alpha^{h} \theta_{j}^{h} & =0, \forall m=1, \ldots, M \\
\sum_{h} \sum_{\omega} \alpha^{h} \zeta^{h}(\omega) \tau_{\ell s}^{h}(\omega) & =0, \forall s=1, \ldots, S ; \ell=1, \ldots L^{s},
\end{aligned}
$$

(ii) for each $h$, it satisfies the consumption-relationship function, $g_{n}^{h}\left(\mathbf{c}^{h}, \mathbf{e}^{h}, \theta^{h}, \tau^{h}, \mathbf{y}^{h}\right)=$ $0, \forall n$

(iii) for each $h, \mathbf{y}^{h}$ follows the production function, $F_{o}^{h}\left(\mathbf{y}^{h}\right)=0, \forall o$;

(iv) for each $h$, it satisfies the obstacle-to-trade constraints:

$$
C_{i, a, a^{\prime}}^{h}\left(\mathbf{c}^{h}, \theta^{h}, \tau^{h}, \mathbf{y}^{h}, \tilde{\mathbf{p}}^{i}, \tilde{\mathbf{P}}^{i}\right) \geq 0, \forall i, a, a^{\prime}
$$

(v) all consistency conditions are satisfied, i.e., $\tilde{\mathbf{p}}^{i}=\tilde{\mathbf{p}}^{i}(\mathbf{c}, \theta, \mathbf{y}, \mathbf{e})$ and $\tilde{\mathbf{P}}^{i}=\tilde{\mathbf{P}}^{i}(\mathbf{c}, \theta, \mathbf{y}, \mathbf{e})$ for all $i$, i.e., prices are such that (46) and (47) are satisfied.

The nonlinearity of obstacle-to-trade constraints could cause the attainable set to be non-convex. This non-convexity implies that randomization, a lottery, could be potentially 
useful. However, for expositional reasons, this section will not use lotteries now. Note that the existence of an externality shown is still true with and without lotteries (Kilenthong and Townsend, 2011). We do generalize and formalize with lotteries in Section 4.1 below.

A constrained optimal allocation (identical within types but this is without loss of generality) is characterized using the following planner's problem, which maximizes the utility of type 1 subject to fixed utility of other types, as follows:

Program 2.

$$
\max _{\mathbf{c}, \theta, \tau, \mathbf{y}} U^{1}\left(\mathbf{c}^{1}\right)
$$

subject to

$$
\begin{aligned}
U^{h}\left(\mathbf{c}^{h}\right) & \geq \overline{\mathscr{U}}^{h}, \text { for } h=2, \ldots, H, \\
g_{n}^{h}\left(\mathbf{c}^{h}, \mathbf{e}^{h}, \theta^{h}, \tau^{h}, \mathbf{y}^{h}\right) & =0, \forall n, h, \\
\sum_{j=1}^{J} \Psi_{m j} \xi_{j} \sum_{h} \alpha^{h} \theta_{j}^{h} & =0, \forall m, \\
\sum_{h} \sum_{\omega} \alpha^{h} \zeta^{h}(\omega) \tau_{\ell s}^{h}(\omega) & =0, \forall l, s, \\
F_{o}^{h}\left(\mathbf{y}^{h}\right) & =0, \forall o, h, \\
C_{i, a, a^{\prime}}^{h}\left(\mathbf{c}^{h}, \theta^{h}, \tau^{h}, \mathbf{y}^{h}, \tilde{\mathbf{p}}^{i}, \tilde{\mathbf{P}}^{i}\right) & \geq 0, \forall i, a, a^{\prime}, h, \\
\tilde{\mathbf{p}}^{i} & =\tilde{\mathbf{p}}^{i}(\mathbf{c}, \theta, \mathbf{y}, \mathbf{e}), \forall i \\
\tilde{\mathbf{P}}^{i} & =\tilde{\mathbf{P}}^{i}(\mathbf{c}, \theta, \mathbf{y}, \mathbf{e}), \forall i,
\end{aligned}
$$

where $\overline{\mathscr{U}}^{h}$ is a promised utility level for an agent of type $h$.

A necessary optimal condition for a Pareto optimal allocation with respect to $y_{\ell}^{h}$ i: ${ }^{5}$

$$
\begin{aligned}
\sum_{n=1}^{N} \mu_{g_{n}}^{h} \frac{\partial g_{n}^{h}}{\partial y_{\ell}^{h}} & +\sum_{o=1}^{O} \mu_{F_{o}}^{h} \frac{\partial F_{o}^{h}}{\partial y_{\ell}^{h}}+\sum_{i=1}^{I} \sum_{a} \sum_{a^{\prime}} \mu_{C_{i, a, a^{\prime}}}^{h} \frac{\partial C_{i, a, a^{\prime}}^{h}}{\partial y_{\ell}^{h}} \\
& +\sum_{\bar{h}=1}^{H} \sum_{i=1}^{I} \sum_{a} \sum_{a^{\prime}} \mu_{C_{i, a, a^{\prime}}}^{\bar{h}}\left[\sum_{l=1}^{L^{i}} \frac{\partial C_{i, a, a^{\prime}}^{\bar{h}}}{\partial \tilde{p}_{l}^{i}} \frac{\partial \tilde{p}_{l}^{i}}{\partial y_{\ell}^{h}}+\sum_{j=1}^{J^{i}} \frac{\partial C_{i, a, a^{\prime}}^{\bar{h}}}{\partial \tilde{P}_{j}^{i}} \frac{\partial \tilde{P}_{j}^{i}}{\partial y_{\ell}^{h}}\right]=0, \forall h,(61)
\end{aligned}
$$

where $\mu_{g_{n}}^{h}, \mu_{F_{o}}^{h}$, and $\mu_{C_{i, a, a^{\prime}}}^{h}$ are the Lagrange multipliers with respect to the $n^{\text {th }}$ consumptionrelationship, (54), the $o^{\text {th }}$ technology constraint, (57), and $\left(i, a, a^{\prime}\right)$ obstacle-to-trade constraint of agent of type $h, 58$, respectively.

\footnotetext{
${ }^{5} \mathrm{~A}$ similar conclusion can be drawn from a necessary optimal condition with respect to $\mathbf{c}_{\ell}^{h}$ and $\theta_{j}^{h}$.
} 
Of special interest, the last term depends not only on the bindingness of obstacle-to-trade constraints for $h$ as we vary $y_{l}^{h}$ but also the bindingness of other agents' $\bar{h}$ obstacle-to-trade constraints. This implies that if any type of agent's obstacle-to-trade constraint is binding, it will impact everyone through prices. This is the source of the price externalities.

Note that an infinitesimal agent takes prices $\mathbf{p}$ and $\mathbf{P}$, including $\tilde{\mathbf{p}}^{i}$ and $\tilde{\mathbf{P}}^{i}$, as invariant. But to the contrary, the constrained planner can influence subsets of prices $\tilde{\mathbf{p}}^{i}$ and $\tilde{\mathbf{P}}^{i}$ through aggregate allocation, $(\mathbf{c}, \theta, \mathbf{y}, \mathbf{e})$. This key influence is the term in $\frac{\partial \tilde{p}_{l}^{i}}{\partial y_{\ell}^{h}}$ and $\frac{\partial \tilde{P}_{j}^{i}}{\partial y_{\ell}^{h}}$ in the planner problem. The difference between the impact of the planner and that of the agents creates price externalities and causes an inefficiency.

Technically, if the last term in (61) were zero, then condition 48) would have been exactly the same as 61 . The last term in 61) could always be zero if either $\mu_{C_{i}}^{\bar{h}}=0$ for all $\bar{h}$ and all $i$, or $\frac{\partial \tilde{p}_{l}^{i}}{\partial y_{\ell}^{h}}=0$ and $\frac{\partial \tilde{P}_{j}^{i}}{\partial y_{\ell}^{h}}=0$, for all $\ell$, all $i$, all $l$, all $j$, and all $h$. Generically, those prices vary with the market fundamental which is determined by $(\mathbf{c}, \theta, \mathbf{y}, \mathbf{e})$. As a result, the last term in 61) will not be zero as long as an obstacle-to-trade constraint of an agent of type $\bar{h}$ binds. With this non-zero term, a competitive equilibrium with obstacles to trade will be constrained inefficient. It is the interaction between the bindingness of obstacle-to-trade constraints and equilibrium prices that is the key to the existence of price externalities.

\section{Market-Based Solution: Endogenous Security Ex- changes}

This section proposes a market-based solution to price externality problems. The solution is to create markets for the rights to trade in a particular security exchange, indexed by $(\tilde{\mathbf{p}}, \tilde{\mathbf{P}}) 6$. The $(\tilde{\mathbf{p}}, \tilde{\mathbf{P}})$ are to be the equilibrium prices for commodities and securities within the specified security exchange, but from the agent stand point all possible price pairs across exchanges are available. Agents pay a market participation fee, or receive a compensation, as fixed fee depending on the exchange, the price pair and rights indexed by $i$. An agent who chooses to trade in a security exchange $(\tilde{\mathbf{p}}, \tilde{\mathbf{P}})$ can act as if she can trade commodities

\footnotetext{
${ }^{6}$ Recall that a subset of these prices enters into the obstacle-to-trade constraint $i, i=1,2, \ldots, I$.
} 
and securities with the specific prices indicated. Importantly, those agents are not allowed to trade with agents in other exchanges $\left(\tilde{\mathbf{p}}^{\prime}, \tilde{\mathbf{P}}^{\prime}\right)$. Formally, this solution concept requires a registration/identification system and an exclusivity assumption; that is, an agent type $h$ in an exchange $(\tilde{\mathbf{p}}, \tilde{\mathbf{P}})$ can trade exclusively within his exchange but not with agents in other exchanges $\left(\tilde{\mathbf{p}}^{\prime}, \tilde{\mathbf{P}}^{\prime}\right)$. Put differently, agents will be sorted into segregated exchanges. For all but the exogenous incomplete market set up, it is sufficient to have exchanges in which securities are actually traded only. For the incomplete market economy, we do not expand the set of securities but simply add segregated exchanges. More generally, we keep track of both security and spot market prices.

Formally, let $\Delta_{i}^{h}\left(\tilde{\mathbf{p}}^{i}, \tilde{\mathbf{P}}^{i}\right)$ denote the amount of the rights to trade in a particular security exchange with specified prices $\left(\tilde{\mathbf{p}}^{i}, \tilde{\mathbf{P}}^{i}\right)$ associated with obstacle-to-trade constraint $i$ for an agent of type $h$. Let $(\tilde{\mathbf{p}}, \tilde{\mathbf{P}}) \equiv\left[\tilde{\mathbf{p}}^{i}, \tilde{\mathbf{P}}^{i}\right]_{i}$ denote a collection of price vectors relevant to each obstacle-to-trade constraint. As there can be multiple constraints, notationally, let $\Delta^{h} \equiv\left[\Delta_{i}^{h}\right]_{i}$ be the associated vector. This object is the externality-correcting commodity vector that, as in standard Walrasian equilibrium, will have its own unit of account market prices, $\Pi_{i}^{\Delta}\left(\tilde{\mathbf{p}}^{i}, \tilde{\mathbf{P}}^{i}\right), i=1,2, \ldots, I$. In order to be eligible to trade in this exchange $(\tilde{\mathbf{p}}, \tilde{\mathbf{P}})$, an agent of type $h$ must hold the rights to trade $\Delta_{i}^{h}\left(\tilde{\mathbf{p}}^{i}, \tilde{\mathbf{P}}^{i}\right)=d_{i}^{h}\left(\mathbf{e}^{h}, \theta^{h}, \mathbf{y}^{h}, \tilde{\mathbf{p}}^{i}, \tilde{\mathbf{P}}^{i}\right)$ for all $i=1,2, \ldots, I$. This depends on agent's type, agent's endowment, agent's choices, and prices. Otherwise, he will not be able to trade in the exchange. For example, in a collateral equilibrium model in Kilenthong and Townsend (2014b), this object is called the "type $h$ discrepancy from the fundamental" in spot markets, which depends on his endowments, his choice of collateral allocation, and the specific price. An alternative example is in Kilenthong and Townsend (2011), in which the rights to trade is implicitly embedded in the incentive comparability constraints. More generally, an agent's required rights to trade can be defined by excess demand functions for relevant commodities, which are again functions of his endowments, his choice of collateral allocation, and the specific price. The right to trade in this paper could be a tax or subsidy in the public finance literature, as discussed in Kilenthong and Townsend (2014b). This paper offers a market-based solution, however. So these are additional market clearing, market formation prices not government instruments. Regulators need only allow proper configuration of exchanges with market participation fees 
competitively determined.

An agent of type $h$ faces a two-step problem. Let $P_{j}(\tilde{\mathbf{p}}, \tilde{\mathbf{P}})$ be the price of security $j$ that can be traded in an exchange $(\tilde{\mathbf{p}}, \tilde{\mathbf{P}})$. First, conditional on being in exchanges $(\tilde{\mathbf{p}}, \tilde{\mathbf{P}})$, the agent chooses the usual allocation $\left(\theta^{h}, \tau^{h}, \mathbf{y}^{h}\right)$, taking all prices $\mathbf{P}, \tilde{\mathbf{p}}, \tilde{\mathbf{P}}, \Pi_{\Delta}$ as given:

$$
V^{h}(\tilde{\mathbf{p}}, \tilde{\mathbf{P}})=\max _{\theta^{h}, \tau^{h}, \mathbf{y}^{h}, \Delta^{h}} U^{h}\left(\mathbf{c}^{h}\right)
$$

subject to the budget constraints, the consumption-relationship constraints, the technology constraints, and the obstacle-to-trade constraints, and the requirement on the rights to trade, respectively, taking as given the choice of exchanges $(\tilde{\mathbf{p}}, \tilde{\mathbf{P}})$ for the moment:

$$
\begin{aligned}
\sum_{j} P_{j}(\tilde{\mathbf{p}}, \tilde{\mathbf{P}}) \theta_{j}^{h}+\sum_{i} \Pi_{i}^{\Delta}\left(\tilde{\mathbf{p}}^{i}, \tilde{\mathbf{P}}^{i}\right) \Delta_{i}^{h}\left(\tilde{\mathbf{p}}^{i}, \tilde{\mathbf{P}}^{i}\right) & \leq 0 \\
\sum_{\ell=1}^{L^{s}} \tilde{p}_{\ell s} \tau_{\ell s}^{h}(\omega) & \leq 0, \forall s, \omega, \\
g_{n}^{h}\left(\mathbf{c}^{h}, \mathbf{e}^{h}, \theta^{h}, \tau^{h}, \mathbf{y}^{h}\right) & =0, \forall n, \\
F_{o}^{h}\left(\mathbf{y}^{h}\right) & =0, \forall o, \\
C_{i, a, a^{\prime}}^{h}\left(\mathbf{c}^{h}, \theta^{h}, \tau^{h}, \mathbf{y}^{h}, \tilde{\mathbf{p}}^{i}, \tilde{\mathbf{P}}^{i}\right) & \geq 0, \forall i, a, a^{\prime} \\
\Delta_{i}^{h}\left(\tilde{\mathbf{p}}^{i}, \tilde{\mathbf{P}}^{i}\right)-d_{i}^{h}\left(\mathbf{e}^{h}, \theta^{h}, \mathbf{y}^{h}, \tilde{\mathbf{p}}^{i}, \tilde{\mathbf{P}}^{i}\right) & =0, \forall i,
\end{aligned}
$$

where the last constraints ensure that each agent must hold the correct amount of the rights to trade in order to be eligible to trade in each exchange.

Second, the agent then chooses a collection of exchanges $(\tilde{\mathbf{p}}, \tilde{\mathbf{P}})$ that gives the largest utility taking all prices as given:

$$
\max _{(\tilde{\mathbf{p}}, \tilde{\mathbf{P}})} V^{h}(\tilde{\mathbf{p}}, \tilde{\mathbf{P}})
$$

We will now write this problem as a one step problem. This representation is a step toward the lottery representation presented below. Let $\delta^{h}(\tilde{\mathbf{p}}, \tilde{\mathbf{P}}) \in\{0,1\}$ be an indicator function indicating agent $h$ 's choice of a collection of exchanges; that is, $\delta^{h}(\tilde{\mathbf{p}}, \tilde{\mathbf{P}})=1$ is the agent chooses to be in exchanges $(\tilde{\mathbf{p}}, \tilde{\mathbf{P}})$, and zero otherwise. Let $\theta^{h}(\tilde{\mathbf{p}}, \tilde{\mathbf{P}}), \tau^{h}(\omega, \tilde{\mathbf{p}}, \tilde{\mathbf{P}})$, and $\mathbf{y}^{h}(\tilde{\mathbf{p}}, \tilde{\mathbf{P}})$ be choices of securities, spot trades, and net outputs of agent $h$ conditional on being in exchanges $(\tilde{\mathbf{p}}, \tilde{\mathbf{P}})$. This notation emphasizes that a feasible allocation depends on where the agent is. 
The utility maximization problem for an agent of type $h$ is as following:

$$
\max _{\delta^{h}(\tilde{\mathbf{p}}, \tilde{\mathbf{P}}), \theta^{h}(\tilde{\mathbf{p}}, \tilde{\mathbf{P}}), \tau^{h}(\omega, \tilde{\mathbf{p}}, \tilde{\mathbf{P}}), \mathbf{y}^{h}(\tilde{\mathbf{p}}, \tilde{\mathbf{P}}), \Delta^{h}(\tilde{\mathbf{p}}, \tilde{\mathbf{P}})} \sum_{(\tilde{\mathbf{p}}, \tilde{\mathbf{P}})} \delta^{h}(\tilde{\mathbf{p}}, \tilde{\mathbf{P}}) U^{h}\left(\mathbf{c}^{h}(\tilde{\mathbf{p}}, \tilde{\mathbf{P}})\right)
$$

subject to budget, technology, and obstacle-to-trade constraints:

$$
\begin{aligned}
& \sum_{\tilde{\mathbf{p}}, \tilde{\mathbf{P}}} \delta^{h}(\tilde{\mathbf{p}}, \tilde{\mathbf{P}})\left[\sum_{j} P_{j}(\tilde{\mathbf{p}}, \tilde{\mathbf{P}}) \theta_{j}^{h}(\tilde{\mathbf{p}}, \tilde{\mathbf{P}})+\sum_{i} \Pi_{i}^{\Delta}\left(\tilde{\mathbf{p}}^{i}, \tilde{\mathbf{P}}^{i}\right) \Delta_{i}^{h}\left(\tilde{\mathbf{p}}^{i}, \tilde{\mathbf{P}}^{i}\right)\right] \leq 0, \\
& \sum_{\tilde{\mathbf{p}}, \tilde{\mathbf{P}}} \delta^{h}(\tilde{\mathbf{p}}, \tilde{\mathbf{P}}) \sum_{\ell=1}^{L^{s}} \tilde{p}_{\ell s} \tau_{\ell s}^{h}(\omega, \tilde{\mathbf{p}}, \tilde{\mathbf{P}}) \leq 0, \forall s, \omega, \\
& \sum_{\tilde{\mathbf{p}}, \tilde{\mathbf{P}}} \delta^{h}(\tilde{\mathbf{p}}, \tilde{\mathbf{P}}) g_{n}^{h}\left(\mathbf{c}^{h}(\tilde{\mathbf{p}}, \tilde{\mathbf{P}}), \mathbf{e}^{h}, \theta^{h}(\tilde{\mathbf{p}}, \tilde{\mathbf{P}}), \tau^{h}(\omega, \tilde{\mathbf{p}}, \tilde{\mathbf{P}}), \mathbf{y}^{h}(\tilde{\mathbf{p}}, \tilde{\mathbf{P}})\right)=0, \forall n, \\
& \sum_{\tilde{\mathbf{p}}, \tilde{\mathbf{P}}} \delta^{h}(\tilde{\mathbf{p}}, \tilde{\mathbf{P}}) F_{o}^{h}\left(\mathbf{y}^{h}(\tilde{\mathbf{p}}, \tilde{\mathbf{P}})\right)=0, \forall o \\
& \sum_{\tilde{\mathbf{p}}, \tilde{\mathbf{P}}} \delta^{h}(\tilde{\mathbf{p}}, \tilde{\mathbf{P}}) C_{i, a, a^{\prime}}^{h}\left(\mathbf{c}^{h}(\tilde{\mathbf{p}}, \tilde{\mathbf{P}}), \theta^{h}(\tilde{\mathbf{p}}, \tilde{\mathbf{P}}), \tau^{h}(\omega, \tilde{\mathbf{p}}, \tilde{\mathbf{P}}), \mathbf{y}^{h}(\tilde{\mathbf{p}}, \tilde{\mathbf{P}}), \tilde{\mathbf{p}}^{i}, \tilde{\mathbf{P}}^{i}\right) \geq 0, \forall i, a, a^{\prime}, \\
& \sum_{\tilde{\mathbf{p}}, \tilde{\mathbf{P}}} \delta^{h}(\tilde{\mathbf{p}}, \tilde{\mathbf{P}})\left[\Delta_{i}^{h}\left(\tilde{\mathbf{p}}^{i}, \tilde{\mathbf{P}}^{i}\right)-d_{i}^{h}\left(\mathbf{e}^{h}, \theta^{h}\left(\tilde{\mathbf{p}}^{i}, \tilde{\mathbf{P}}^{i}\right), \mathbf{y}^{h}\left(\tilde{\mathbf{p}}^{i}, \tilde{\mathbf{P}}^{i}\right), \tilde{\mathbf{p}}^{i}, \tilde{\mathbf{P}}^{i}\right)\right]=0, \forall i .
\end{aligned}
$$

Our market-based solution requires that we create segregated security exchanges only for securities and commodities whose prices generate price externalities through obstacle-totrade constraints. Some securities are commonly available to trade for all agents regardless of where they are in. For example, spot trades $\theta_{k 0}^{h}$ in the collateral economy in section ?? are commonly traded securities. More formally, let $J^{i}$ denote the set of all securities corresponding to the $i^{\text {th }}$ set of obstacle-to-trade constraint, and therefore will be exclusively available to agents in a particular exchange only. Accordingly, $\tilde{J}=J \backslash \cup_{i} J^{i}$ is the set of all commonly traded securities.

The representative financial intermediary, taking prices $P_{j}(\tilde{\mathbf{p}}, \tilde{\mathbf{P}})$ as given, maximizes its profit

$$
\max _{\psi_{j}} \sum_{\tilde{\mathbf{p}}, \tilde{\mathbf{P}}} \sum_{j} P_{j}(\tilde{\mathbf{p}}, \tilde{\mathbf{P}}) \xi_{j} \psi_{j}(\tilde{\mathbf{p}}, \tilde{\mathbf{P}})
$$


subject to feasibility constraints

$$
\begin{aligned}
\sum_{j \in \tilde{J}} \Psi_{m j} \xi_{j} \sum_{\tilde{\mathbf{p}}, \tilde{\mathbf{P}}} \psi_{j}(\tilde{\mathbf{p}}, \tilde{\mathbf{P}}) & =0, \forall m=1, \ldots, M \\
\sum_{j \in J^{i}} \Psi_{m j} \xi_{j} \sum_{\tilde{\mathbf{p}}_{-i}, \tilde{\mathbf{P}}_{-i}} \psi_{j}(\tilde{\mathbf{p}}, \tilde{\mathbf{P}}) & =0, \forall m=1, \ldots, M ; i=1, \ldots, I ; \tilde{\mathbf{p}}^{i}, \tilde{\mathbf{P}}^{i},
\end{aligned}
$$

where $(\tilde{\mathbf{p}}, \tilde{\mathbf{P}})=\left(\tilde{\mathbf{p}}^{i}, \tilde{\mathbf{P}}^{i}, \tilde{\mathbf{p}}_{-i}, \tilde{\mathbf{P}}_{-i}\right)$. Note that conditions 72 are for securities that are commonly available to trade for all agents and while conditions (73) are for securities that are exclusively available to agents within an exchange $\left(\tilde{\mathbf{p}}^{i}, \tilde{\mathbf{P}}^{i}\right)$ only.

The market clearing constraints for commonly traded securities $j \in \tilde{J}$, and for securities $j \in J^{i}$ exclusively traded within an exchange $\left(\tilde{\mathbf{p}}^{i}, \tilde{\mathbf{P}}^{i}\right)$ are as follows:

$$
\begin{aligned}
\sum_{\tilde{\mathbf{p}}, \tilde{\mathbf{P}}} \sum_{h} \delta^{h}(\tilde{\mathbf{p}}, \tilde{\mathbf{P}}) \alpha^{h} \theta_{j}^{h}(\tilde{\mathbf{p}}, \tilde{\mathbf{P}}) & \leq \sum_{\tilde{\mathbf{p}}, \tilde{\mathbf{P}}} \psi_{j}(\tilde{\mathbf{p}}, \tilde{\mathbf{P}}), \forall j \in \tilde{J} \\
\sum_{\tilde{\mathbf{p}}_{-i}, \tilde{\mathbf{P}}_{-i}} \sum_{h} \delta^{h}(\tilde{\mathbf{p}}, \tilde{\mathbf{P}}) \alpha^{h} \theta_{j}^{h}(\tilde{\mathbf{p}}, \tilde{\mathbf{P}}) & \leq \sum_{\tilde{\mathbf{p}}_{-i}, \tilde{\mathbf{P}}_{-i}} \psi_{j}(\tilde{\mathbf{p}}, \tilde{\mathbf{P}}), \forall j \in J^{i} ; i ; \tilde{\mathbf{p}}^{i}, \tilde{\mathbf{P}}^{i} .
\end{aligned}
$$

Similarly, the market clearing constraints for every spot markets $L^{s}$ in an exchange $\left(\tilde{\mathbf{p}}^{i}, \tilde{\mathbf{P}}^{i}\right)$ are as follows:

$$
\sum_{\tilde{\mathbf{p}}_{-i}, \tilde{\mathbf{P}}_{-i}} \sum_{h} \sum_{\omega} \delta^{h}(\tilde{\mathbf{p}}, \tilde{\mathbf{P}}) \alpha^{h} \zeta^{h}(\omega) \tau_{\ell s}^{h}(\omega, \tilde{\mathbf{p}}, \tilde{\mathbf{P}}) \leq 0, \forall s \in S ; \ell \in L^{s} ; \tilde{\mathbf{p}}^{i}, \tilde{\mathbf{P}}^{i}
$$

In addition, we require that the markets for the rights to trade clear; that is, for each exchange $\left(\tilde{\mathbf{p}}^{i}, \tilde{\mathbf{P}}^{i}\right)$,

$$
\sum_{\tilde{\mathbf{p}}_{-i}, \tilde{\mathbf{P}}_{-i}} \sum_{h} \delta^{h}(\tilde{\mathbf{p}}, \tilde{\mathbf{P}}) \alpha^{h} \Delta_{i}^{h}\left(\tilde{\mathbf{p}}^{i}, \tilde{\mathbf{P}}^{i}\right) \leq 0, \forall i, \tilde{\mathbf{p}}^{i}, \tilde{\mathbf{P}}^{i}
$$

These constraints are called consistency constraints, which ensure that equilibrium prices of relevant commodities and securities in each exchange are $\left(\tilde{\mathbf{p}}^{i}, \tilde{\mathbf{P}}^{i}\right)$ as specified.

\subsection{The Lottery Representation}

We will now proceed with more formality. Because the obstacle-to-trade constraints can potentially generate non-convexity problems, lotteries will be applied. 
Let $x^{h}(\mathbf{c}, \theta, \tau, \mathbf{y}, \tilde{\mathbf{p}}, \tilde{\mathbf{P}}, \Delta)$ be the probability measure on $(\mathbf{c}, \theta, \tau, \mathbf{y}, \tilde{\mathbf{p}}, \tilde{\mathbf{P}}, \Delta)$ for an agent of type $h$. In other words, $x^{h}(\mathbf{c}, \theta, \tau, \mathbf{y}, \tilde{\mathbf{p}}, \tilde{\mathbf{P}}, \Delta)$ is the probability of receiving allocation $(\mathbf{c}, \theta, \tau, \mathbf{y})$, and being in exchanges $(\tilde{\mathbf{p}}, \tilde{\mathbf{P}})$ with the rights to trade $\Delta$. It is worthy of emphasis that price externalities cannot simply be overcome using lotteries to convexify the problem, as shown in Kilenthong and Townsend (2011) where price externalities exist even in a setting with lotteries.

As a probability measure, a lottery of an agent of type $h, x^{h}$, satisfies the following probability constraint:

$$
\sum_{\mathbf{c}, \theta, \tau, \mathbf{y}, \tilde{\mathbf{p}}, \tilde{\mathbf{P}}, \Delta} x^{h}(\mathbf{c}, \theta, \tau, \mathbf{y}, \tilde{\mathbf{p}}, \tilde{\mathbf{P}}, \Delta)=1 .
$$

With a continuum of agents, $x^{h}(\mathbf{c}, \theta, \tau, \mathbf{y}, \tilde{\mathbf{p}}, \tilde{\mathbf{P}}, \Delta)$ can be interpreted as the fraction of agents of type $h$ assigned to a bundle $(\mathbf{c}, \theta, \tau, \mathbf{y}, \tilde{\mathbf{p}}, \tilde{\mathbf{P}}, \Delta)$. More formally, with all choice object gridded up as an approximation, the commodity space is assumed to be a finite dimensional linear space ${ }^{7}$. Let $\mathbf{x}^{h} \equiv\left[x^{h}(\mathbf{c}, \theta, \tau, \mathbf{y}, \tilde{\mathbf{p}}, \tilde{\mathbf{P}}, \Delta)\right]_{(\mathbf{c}, \theta, \tau, \mathbf{y}, \tilde{\mathbf{P}}, \tilde{\mathbf{P}}, \Delta)}$ be a typical lottery for an agent of type $h$.

We now consider a bundle $(\mathbf{c}, \theta, \tau, \mathbf{y}, \tilde{\mathbf{p}}, \tilde{\mathbf{P}}, \Delta)$ as a typical commodity. Each bundle will be feasible for an agent of type $h$ with endowment $\mathbf{e}$ only if it satisfies the spot-market budget constraints, the consumption-relationship constraints, the technology constraints, the obstacle-to-trade constraints, and the right-to-trade requirement: 8 as following:

$$
\begin{aligned}
\sum_{\ell=1}^{L^{s}} \tilde{p}_{\ell s} \tau_{\ell s}^{h}(\omega) & \leq 0, \forall s, \omega, \\
g_{n}^{h}\left(\mathbf{c}^{h}, \mathbf{e}^{h}, \theta^{h}, \tau^{h}, \mathbf{y}^{h}\right) & =0, \forall n, \\
F_{o}^{h}\left(\mathbf{y}^{h}\right) & =0, \forall o, \\
C_{i, a, a^{\prime}}^{h}\left(\mathbf{c}^{h}, \theta^{h}, \tau^{h}, \mathbf{y}^{h}, \tilde{\mathbf{p}}^{i}, \tilde{\mathbf{P}}^{i}\right) & \geq 0, \forall i, a, a^{\prime} \\
\Delta_{i}^{h}\left(\tilde{\mathbf{p}}^{i}, \tilde{\mathbf{P}}^{i}\right)-d_{i}^{h}\left(\mathbf{e}^{h}, \theta^{h}, \mathbf{y}^{h}, \tilde{\mathbf{p}}^{i}, \tilde{\mathbf{P}}^{i}\right) & =0, \forall i,
\end{aligned}
$$

\footnotetext{
${ }^{7}$ The limiting arguments under weak-topology used in Prescott and Townsend (1984a) can be applied to establish the results if the commodity space is not finite.

${ }^{8}$ In some cases, as in a moral hazard with retrading and a hidden information with retrading, the rightto-trade requirements may be embedded implicitly in the obstacle-to-trade constraints. As a result, they may not be explicitly written out as separate constraints as in Kilenthong and Townsend (2011).
} 
Accordingly, we impose the following condition on the probability measure as follows:

$$
\begin{aligned}
x^{h}(\mathbf{c}, \theta, \tau, \mathbf{y}, \tilde{\mathbf{p}}, \tilde{\mathbf{P}}, \Delta) & \geq 0 \text { if conditions } 79 \text { to } 83 \text { hold, } \\
& =0 \text { if otherwise. }
\end{aligned}
$$

In words, a positive measure can be defined only on feasible bundles, which satisfy the spot-market budget constraints, the consumption-relationship constraints, the technology constraints, the obstacle-to-trade constraints, have the required amount of the rights to trade.

In addition, in order to incorporate the moral hazard economy into the general framework with lotteries, we need to impose additional conditions, called mother-nature constraints, to ensure that the lottery is consistent with the production technology 9 , as in Prescott and Townsend (1984b). There are $W$ mother-nature constraints. The mother-nature constraints can be written as linear constraints as follows:

$$
\sum_{\mathbf{c}, \theta, \tau, \mathbf{y}, \tilde{\mathbf{P}}, \tilde{\mathbf{P}}, \Delta} \Gamma_{w}(\mathbf{c}, \theta, \tau, \mathbf{y}, \tilde{\mathbf{p}}, \tilde{\mathbf{P}}, \Delta) x^{h}(\mathbf{c}, \theta, \tau, \mathbf{y}, \tilde{\mathbf{p}}, \tilde{\mathbf{P}}, \Delta)=0
$$

where $\Gamma_{w}(\mathbf{c}, \theta, \tau, \mathbf{y}, \tilde{\mathbf{p}}, \tilde{\mathbf{P}}, \Delta) \in \mathbb{R}$ is the coefficient for $w^{\text {th }}$ constraint corresponding for $(\mathbf{c}, \theta, \tau, \mathbf{y}, \tilde{\mathbf{p}}, \tilde{\mathbf{P}}, \Delta)$.

More formally, the consumption possibility set of an agent of type $h$ is defined as follows:

$$
X^{h}=\left\{\mathbf{x}^{h}: x^{h}(\mathbf{c}, \theta, \tau, \mathbf{y}, \tilde{\mathbf{p}}, \tilde{\mathbf{P}}, \Delta) \text { satisfies } 88, \text {, 84), and (85) }\right\}
$$

Let $\mathbf{x}^{h}$ be a typical element of $X^{h}$. Note that $X^{h}$ is compact and convex.

\subsection{Competitive Equilibrium with Segregated Security Exchanges}

Let $P(\mathbf{c}, \theta, \tau, \mathbf{y}, \tilde{\mathbf{p}}, \tilde{\mathbf{P}}, \Delta)$ be the price of a bundle or $\operatorname{contract}(\mathbf{c}, \theta, \tau, \mathbf{y}, \tilde{\mathbf{p}}, \tilde{\mathbf{P}}, \Delta)$. Each agent is infinitesimally small relative to the entire economy and will take all prices as given. The intermediaries also act competitively. Note as well that the rights to trade $\Delta$ is also priced.

\footnotetext{
${ }^{9}$ That is, the technology constraints will be replaced by the mother-nature constraints for the moral hazard with retrading economy.
} 
Consumers: Each agent of type $h$, taking prices $P(\mathbf{c}, \theta, \tau, \mathbf{y}, \tilde{\mathbf{p}}, \tilde{\mathbf{P}}, \Delta)$ as given, chooses $\mathbf{x}^{h}$ to maximize its expected utility:

$$
\max _{\mathbf{x}^{h} \in X^{h}} \sum_{\mathbf{c}, \theta, \tau, \mathbf{y}, \tilde{\mathbf{p}}, \tilde{\mathbf{P}}, \Delta} x^{h}(\mathbf{c}, \theta, \tau, \mathbf{y}, \tilde{\mathbf{p}}, \tilde{\mathbf{P}}, \Delta) U^{h}(\mathbf{c})
$$

subject to the budget constraint

$$
\sum_{\mathbf{c}, \theta, \tau, \mathbf{y}, \tilde{\mathbf{p}}, \tilde{\mathbf{P}}, \Delta} P(\mathbf{c}, \theta, \tau, \mathbf{y}, \tilde{\mathbf{p}}, \tilde{\mathbf{P}}, \Delta) x^{h}(\mathbf{c}, \theta, \tau, \mathbf{y}, \tilde{\mathbf{p}}, \tilde{\mathbf{P}}, \Delta) \leq 0
$$

Financial Intermediaries: As in section 2, there is no loss of generality to assume that there is a representative financial intermediary who issues (sells) $b(\mathbf{c}, \theta, \tau, \mathbf{y}, \tilde{\mathbf{p}}, \tilde{\mathbf{P}}, \Delta) \in \mathbb{R}_{+}$ units of each bundle at the unit price $P(\mathbf{c}, \theta, \tau, \mathbf{y}, \tilde{\mathbf{p}}, \tilde{\mathbf{P}}, \Delta)$. Note that the intermediary can issue any non-negative number of a bundle; that is, the number of bundles issued does not have to be between zero and one and is not a lottery. Let $\mathbf{b}$ be the vector of the number of bundles issued as one move across bundles, arguments in $b(\mathbf{c}, \theta, \tau, \mathbf{y}, \tilde{\mathbf{p}}, \tilde{\mathbf{P}}, \Delta)$. With constant returns to scale, the profit of a market-maker must be zero and the number of market-makers becomes irrelevant. Therefore, without loss of generality, we assume there is one representative market-maker, which takes prices as given.

The intermediary's profit maximization problem is as follows:

$$
\max _{\mathbf{b}} \sum_{\mathbf{c}, \theta, \tau, \mathbf{y}, \tilde{\mathbf{p}}, \tilde{\mathbf{P}}, \Delta} P(\mathbf{c}, \theta, \tau, \mathbf{y}, \tilde{\mathbf{p}}, \tilde{\mathbf{P}}, \Delta) b(\mathbf{c}, \theta, \tau, \mathbf{y}, \tilde{\mathbf{p}}, \tilde{\mathbf{P}}, \Delta)
$$

subject to

$$
\begin{aligned}
& \sum_{j \in J \backslash \tilde{J}} \sum_{(\mathbf{c}, \theta, \tau, \mathbf{y}, \tilde{\mathbf{p}}, \tilde{\mathbf{P}}, \Delta)} b(\mathbf{c}, \theta, \tau, \mathbf{y}, \tilde{\mathbf{p}}, \tilde{\mathbf{P}}, \Delta) \Psi_{m j} \xi_{j} \theta_{j} \leq 0, \forall m, \\
& \sum_{j \in \tilde{J}^{i}} \sum_{\left(\mathbf{c}, \theta, \tau, \mathbf{y}, \tilde{\mathbf{p}}_{-i}, \tilde{\mathbf{P}}_{-i}, \Delta\right)} b(\mathbf{c}, \theta, \tau, \mathbf{y}, \tilde{\mathbf{p}}, \tilde{\mathbf{P}}, \Delta) \Psi_{m j} \xi_{j} \theta_{j} \leq 0, \forall m ; i ; \tilde{\mathbf{p}}^{i}, \tilde{\mathbf{P}}^{i} .
\end{aligned}
$$

These constraints state that the financial intermediary must put together deals that execute all securities properly.

Market Clearing: The market-clearing conditions for contracts/lotteries are as follows:

$$
\sum_{h} \alpha^{h} x^{h}(\mathbf{c}, \theta, \tau, \mathbf{y}, \tilde{\mathbf{p}}, \tilde{\mathbf{P}}, \Delta)=b(\mathbf{c}, \theta, \tau, \mathbf{y}, \tilde{\mathbf{p}}, \tilde{\mathbf{P}}, \Delta), \forall(\mathbf{c}, \theta, \tau, \mathbf{y}, \tilde{\mathbf{p}}, \tilde{\mathbf{P}}, \Delta)
$$


In order to define the market-clearing conditions for spot trades consistently, we need to define indicator functions $\rho_{s i}$ whose value will be one if restricted markets $s$ are relevant to obstacle-to-trade constraints $i$, and zero otherwise. More formally, $\rho_{s i}=1$ if $\tilde{p}_{s}=\tilde{p}_{i}$, and $\rho_{s i}=0$ otherwise. The market-clearing conditions for spot trades are as follows:

$$
\sum_{\left(\mathbf{c}, \theta, \tau_{-\ell-s}, \mathbf{y}, \tilde{\mathbf{p}}_{-i}, \tilde{\mathbf{P}}_{-i}, \Delta\right)} \sum_{h} \alpha^{h} x^{h}(\mathbf{c}, \theta, \tau, \mathbf{y}, \tilde{\mathbf{p}}, \tilde{\mathbf{P}}, \Delta) \tau_{\ell s} \rho_{s i}=0, \forall s ; \ell ; i ; \tilde{\mathbf{p}}^{i}, \tilde{\mathbf{P}}^{i}
$$

where $\tau=\left(\tau_{\ell s}, \tau_{-\ell-s}\right)$. Note that the ex-post diversity is already captured implicitly in the lottery $x^{h}$, and therefore there is no need for $\zeta^{h}(\omega)$ in the lottery representation. For example, as in the moral hazard case, $\zeta^{h}(\mathbf{q}, a)=\delta(a) f(\mathbf{q} \mid a)$ represents a fraction of population who took action $a$ and received outputs $\mathbf{q}$. Under the lottery representation, the mother nature constraints ensure that these fractions are consistent with the production technology. That is, the ex-post diversity is already part of the lottery.

In addition, we again require that the markets for the rights to trade clear; that is, for each exchange $\left(\tilde{\mathbf{p}}^{i}, \tilde{\mathbf{P}}^{i}\right)$,

$$
\sum_{\left(\mathbf{c}, \theta, \tau, \mathbf{y}, \tilde{\mathbf{p}}_{-i}, \tilde{\mathbf{P}}_{-i}, \Delta\right)} \sum_{h} \alpha^{h} x^{h}(\mathbf{c}, \theta, \tau, \mathbf{y}, \tilde{\mathbf{p}}, \tilde{\mathbf{P}}, \Delta) \Delta_{i}^{h}=0, \forall i ; \tilde{\mathbf{p}}^{i}, \tilde{\mathbf{P}}^{i}
$$

Definition 3. A competitive equilibrium with segregated exchanges is a specification of allocation $(\mathbf{x}, \mathbf{b})$, and prices $P(\mathbf{c}, \theta, \tau, \mathbf{y}, \tilde{\mathbf{p}}, \tilde{\mathbf{P}}, \Delta)$ such that

(i) for each agent of type $h, \mathbf{x}^{h} \in X^{h}$ solves 87 subject to 88 , taking prices $P(\mathbf{c}, \theta, \tau, \mathbf{y}, \tilde{\mathbf{p}}, \tilde{\mathbf{P}}, \Delta)$ as given;

(ii) for the financial intermediary, b solves 89 subject to 90,91 , taking prices $P(\mathbf{c}, \theta, \tau, \mathbf{y}, \tilde{\mathbf{p}}, \tilde{\mathbf{P}}, \Delta)$ as given;

(iii) markets for contracts/lotteries, spot trades, and rights to trade clear; that is, (92), (93) and (94) hold.

\subsection{Constrained Optimal Allocations}

An allocation $\mathbf{x} \equiv\left(\mathbf{x}^{h}\right)_{h}$ is attainable if $\mathbf{x}^{h} \in X^{h}$ for all $h$, and it satisfies the following resource constraints for common securities, for securities corresponding to the $i^{\text {th }}$ obstacle- 
to-trade constraint in exchange $\left(\tilde{\mathbf{p}}^{i}, \tilde{\mathbf{P}}^{i}\right)$, for spot trades $\tau_{\ell s}$ in exchange $\left(\tilde{\mathbf{p}}^{i}, \tilde{\mathbf{P}}^{i}\right)$, and the consistency constraints, respectively:

$$
\begin{aligned}
\sum_{j \in J \backslash \tilde{J}} \sum_{(\mathbf{c}, \theta, \tau, \mathbf{y}, \tilde{\mathbf{p}}, \tilde{\mathbf{P}}, \Delta)} \sum_{h} \alpha^{h} x^{h}(\mathbf{c}, \theta, \tau, \mathbf{y}, \tilde{\mathbf{p}}, \tilde{\mathbf{P}}, \Delta) \Psi_{m j} \xi_{j} \theta_{j} & \leq 0, \forall m, \\
\sum_{j \in \tilde{J}^{i}} \sum_{\left(\mathbf{c}, \theta, \tau, \mathbf{y}, \tilde{\mathbf{p}}_{-i}, \tilde{\mathbf{P}}_{-i}, \Delta\right)} \sum_{h} \alpha^{h} x^{h}(\mathbf{c}, \theta, \tau, \mathbf{y}, \tilde{\mathbf{p}}, \tilde{\mathbf{P}}, \Delta) \Psi_{m j} \xi_{j} \theta_{j} & \leq 0, \forall m ; i ; \tilde{\mathbf{p}}^{i}, \tilde{\mathbf{P}}^{i}, \\
\sum_{\left(\mathbf{c}, \theta, \tau_{-\ell-s}, \mathbf{y}, \tilde{\mathbf{p}}_{-i}, \tilde{\mathbf{P}}_{-i}, \Delta\right)} \sum_{h} \alpha^{h} x^{h}(\mathbf{c}, \theta, \tau, \mathbf{y}, \tilde{\mathbf{p}}, \tilde{\mathbf{P}}, \Delta) \tau_{\ell s} \rho_{s i} & =0, \forall s ; \ell ; i ; \tilde{\mathbf{p}}^{i}, \tilde{\mathbf{P}}^{i}, \\
\sum_{\left(\mathbf{c}, \theta, \tau, \mathbf{y}, \tilde{\mathbf{p}}_{-i}, \tilde{\mathbf{P}}_{-i}, \Delta\right)} \sum_{h} \alpha^{h} x^{h}(\mathbf{c}, \theta, \tau, \mathbf{y}, \tilde{\mathbf{p}}, \tilde{\mathbf{P}}, \Delta) \Delta_{i}^{h} & =0, \forall i ; \tilde{\mathbf{p}}^{i}, \tilde{\mathbf{P}}^{i} .
\end{aligned}
$$

The key idea of our market-based solution is to formulate the consistency constraints as linear feasibility constraints. This formulation in fact makes the price externalities depletable, and therefore makes it possible to reach a constrained optimal allocation using a non-personalized price system as in a standard Walrasian equilibrium in contrast to a Lindahl equilibrium where prices are personalized. Technically, the linear consistency constraints correspond to market clearing conditions for the rights to trade in the competitive equilibrium.

Definition 4. An allocation $\mathbf{x} \equiv\left(\mathbf{x}^{h}\right)_{h=1}^{H} \in X^{1} \times \ldots \times X^{H}$ is said to be attainable if $\mathbf{x}^{h} \in X^{h}$ for every agent of type $h$, and it satisfies $95-(98)$.

Let $X$ denote the set of all attainable allocations. With finite linear weak-inequality constraints, the attainable set $X$ is compact and convex. In addition, the assumption that the endowment is on the grids also ensures that $X$ is nonempty.

A constrained optimal allocation is an attainable allocation such that there is no other attainable allocation that can make at least one agent type strictly better off without making any other agent type worse off. We characterize constrained optimality using the following Pareto program. Let $\lambda^{h} \geq 0$ be the Pareto weight of agent type $h$. There is no loss of generality to normalize the weights such that $\sum_{h} \lambda^{h}=1$. A constrained Pareto optimal allocation $\mathrm{x}$ solves the following Pareto program. 
Program 3. The Pareto Program with Lotteries:

$$
\max _{\mathbf{x} \in X} \sum_{h} \lambda^{h} \alpha^{h} \sum_{\mathbf{c}, \theta, \tau, \mathbf{y}, \tilde{\mathbf{p}}, \tilde{\mathbf{P}}, \Delta} x^{h}(\mathbf{c}, \theta, \tau, \mathbf{y}, \tilde{\mathbf{p}}, \tilde{\mathbf{P}}, \Delta) U^{h}(\mathbf{c})
$$

subject to $95-(98)$.

It is clear that the objective function now is linear in $\mathbf{x}$. Thus, it is continuous and weakly concave. As discussed earlier, the feasible set $X$ is non-empty, compact, and convex. Therefore, a solution to the Pareto program for given positive Pareto weights exists and is a global maximum. The proof of the equivalence between Pareto optimal allocations and the solutions to the program is omitted for brevity (see Prescott and Townsend, 1984b, for a similar proof).

\subsection{Welfare Theorems and Existence Theorem}

As in the classical general equilibrium model, the economy is a well-defined convex economy, i.e., the commodity space is Euclidean, the consumption set is compact and convex, the utility function is linear. As a result, the first and second welfare theorems hold, and a competitive equilibrium exists. In particular, this section proves that the competitive equilibrium is constrained optimal and any constrained optimal allocation can be supported by a competitive equilibrium with transfers. Then, we will use Negishi's method to prove the existence of a competitive equilibrium. Because all the proofs in this section are standard, we omitted them.

The standard contradiction argument will be used to prove the following first welfare theorem. We also assume that there is no local satiation point in the consumption set.

Assumption 1. For any $\mathbf{x}^{h} \in X^{h}$, there exists $\tilde{\mathbf{x}}^{h} \in X^{h}$ such that

$$
\sum_{\mathbf{c}, \theta, \tau, \mathbf{y}, \tilde{\mathbf{p}}, \tilde{\mathbf{P}}, \Delta} \tilde{x}^{h}(\mathbf{c}, \theta, \tau, \mathbf{y}, \tilde{\mathbf{p}}, \tilde{\mathbf{P}}, \Delta) U^{h}(\mathbf{c})>\sum_{\mathbf{c}, \theta, \tau, \mathbf{y}, \tilde{\mathbf{P}}, \tilde{\mathbf{P}}, \Delta} x^{h}(\mathbf{c}, \theta, \tau, \mathbf{y}, \tilde{\mathbf{p}}, \tilde{\mathbf{P}}, \Delta) U^{h}(\mathbf{c}) .
$$

Based on this no local satiation assumption, we can prove the following first welfare theorem.

Theorem 1. With local nonsatiation of preferences (Assumption 1), a competitive equilibrium with segregated exchanges allocation is (constrained) Pareto optimal. 
The Second Welfare theorem states that any Pareto optimal allocation, corresponding to strictly positive Pareto weights, can be supported as a competitive equilibrium with transfers. The standard approach applies here. In particular, we first prove that any constrained optimal allocation can be decentralized as a compensated equilibrium. Then, we use a standard cheaper-point argument (see Debreu, 1954) to show that any compensated equilibrium is a competitive equilibrium with transfers.

Theorem 2. Any Pareto optimal allocation corresponding with strictly positive Pareto weights $\lambda^{h}>0, \forall h$ can be supported as a competitive equilibrium with segregated exchanges with transfers.

We use Negishi's mapping method (Negishi, 1960) to prove the existence of competitive equilibrium. The proof benefits from the second welfare theorem. Specifically, a part of the mapping applies the theorem in that the solution to the Pareto program is a competitive equilibrium with transfers. We then show that a fixed-point of the mapping exists and it represents a competitive equilibrium without transfers.

Theorem 3. For any positive endowments, a competitive equilibrium with segregated exchanges exists.

\section{Conclusion}

We offer a general approach to the problem of pecuniary externalities that encompasses six leading example economies in the literature. Namely, we expand the underlying commodity space of the environment of a generalized equilibrium model, allow bundling and exclusivity, and devise a general method that entirely internalizes these externalities. The two principal welfare theorems apply to the generalize environment and hence of the six example economies individually: competitive equilibria are constrained efficient, and any constrained Pareto optimal allocation can be achieved in competitive markets with suitable lump sum transfers and taxes.

Putting the result this way may make it seem that our paper is a lesson in abstract general equilibrium theory and limited to the interest of theorists. Yet to the contrary, we 
are motivated by recent policy discussions on fire sales and balance sheet amplifiers and the forms of consequent regulation. Our goal is to use theory to contribute to those discussions. We show simply if not radically that there is an alternative to the current and recommended regulations. That is, there is way to structure financial markets, with competitively priced rights to trade, so that pecuniary externalities are internalized and equilibria are constrained efficient. Further, the platforms with registration, tracking, and exclusivity that are required for implementation of our proposal are no more demanding than the technology already used in the routine operation of contemporary financial markets and indeed used or promoted in recent regulation. We only require that ownership of securities be transferred electronically on platforms and that traders and trades be registered and recorded (see a detailed discussion in Kilenthong and Townsend, 2014a). The optimal form of ex ante market structure using these technologies is the punchline recommendation of the paper.

\section{References}

Acemoglu, D. and A. Simsek (2012). Moral Hazard and Efficiency in General Equilibrium with Anonymous Trading. Working Paper.

Allen, F. and D. Gale (2004). Financial Intermediaries and Markets. Econometrica, 10231061.

Araujo, A., F. Kubler, and S. Schommer (2012). Regulating collateral-requirements when markets are incomplete. Journal of Economic Theory 147(2), 450-476.

Arrow, K. (1969). The Organization of Economic Activity: Issues Pertinent to the Choice of Market versus Nonmarket Allocation. The Analysis and Evaluation of Public Expenditure: The PPB System 1, 59-73.

Begalle, B., A. Martin, J. McAndrews, and S. McLaughlin (2013). The risk of fire sales in the tri-party repo market. Technical report, Federal Reserve Bank of New York.

Bianchi, J. and E. Mendoza (2012). Overborrowing, financial crises and macro-prudential policy. Working Papers. 
Bisin, A. and P. Gottardi (2006). Efficient Competitive Equilibria with Adverse Selection. Journal of Political Economy 114(3), 485-516.

Caballero, R. and A. Krishnamurthy (2001). International and Domestic Collateral Constraints in a Model of Emerging Market Crises. Journal of Monetary Economics 48(3), $513-548$.

Debreu, G. (1954). Valuation Equilibrium and Pareto Optimum. Proceedings of the National Academy of Sciences of the United States of America 40(7), 588.

Diamond, D. and P. Dybvig (1983). Bank Runs, Deposit Insurance, and Liquidity. The Journal of Political Economy $91(3), 401$.

Farhi, E., M. Golosov, and A. Tsyvinski (2009, 07). A Theory of Liquidity and Regulation of Financial Intermediation. Review of Economic Studies 76(3), 973-992.

Farhi, E. and I. Werning (2013). On the Inefficiency of Financial Market Equilibria in Macroeconomics Models with Nominal Rigidities. Technical report, Harvard Working paper.

Geanakoplos, J. (2009). The Leaverage Cycles. Working Paper.

Geanakoplos, J. and H. Polemarchakis (1986). Existence, Regularity and Constrained Suboptimality of Competitive Allocations when the Asset Market is Incomplete. Uncertainty, Information and Communication: Essays in Honor of KJ Arrow 3, 65-96.

Geanakoplos, J. and H. Polemarchakis (2008). Pareto improving taxes. Journal of Mathematical Economics 44(7), 682-696.

Gorton, G. and A. Metrick (2012). Securitized banking and the run on repo. Journal of Financial Economics 104(3), 425-451.

Greenwald, B. and J. Stiglitz (1986). Externalities in Economies with Imperfect Information and Incomplete Markets. Quarterly Journal of Economics 101(2), 229-264.

Guerrieri, V., R. Shimer, and R. Wright (2010). Adverse selection in competitive search equilibrium. Econometrica 78(6), 1823-1862. 
Hart, O. D. and L. Zingales (2113). Inefficient Provision of Liquidity. Technical report, Working Paper.

Herings, P. J.-J. and H. Polemarchakis (2005). Pareto improving price regulation when the asset market is incomplete. Economic Theory 25(1), 135-154.

Hornstein, A. and E. C. Prescott (1993). The firm and the plant in general equilibrium theory. General equilibrium, growth, and trade 2, 393-410.

Jacklin, C. (1987). Demand Deposits, Trading Restrictions, and Risk Sharing. Contractual Arrangements for Intertemporal Trade, 26-47.

Jeanne, O. and A. Korinek (2010). Managing credit booms and busts: A pigouvian taxation approach. Technical report, National Bureau of Economic Research.

Kilenthong, W. T. and R. M. Townsend (2011). Information-Constrained Optima with Retrading: An Externality and its Market-Based Solution. Journal of economic theory $146(3), 1042-1077$.

Kilenthong, W. T. and R. M. Townsend (2014a). A Market Based Solution to Price Externalities: A Generalized Framework. Working Paper.

Kilenthong, W. T. and R. M. Townsend (2014b). Segregated Security Exchanges with Ex Ante Rights to Trade. Working Paper.

Koopmans, T. C. and M. Beckmann (1957). Assignment problems and the location of economic activities. Econometrica, 53-76.

Korinek, A. (2010). Regulating capital flows to emerging markets: An externality view. Working Paper.

Krishnamurthy, A., S. Nagel, and D. Orlov (2012). Sizing up repo. Technical report, National Bureau of Economic Research.

Lorenzoni, G. (2008). Inefficient Credit Booms. Review of Economic Studies 75(3), 809-833. 
McKenzie, L. W. (1959). On the existence of general equilibrium for a competitive market. Econometrica: journal of the Econometric Society, 54-71.

McKenzie, L. W. (1981). The classical theorem on existence of competitive equilibrium. Econometrica, 819-841.

Meade, J. E. (1952). External Economies and Diseconomies in a Competitive Situation. The economic journal, 54-67.

Mortensen, D. T. and R. Wright (2002). Competitive pricing and efficiency in search equilibrium*. International Economic Review 43(1), 1-20.

Negishi, T. (1960). Welfare Economics and Existence of an Equilibrium for a Competitive Economy. Metroeconomica 12(2-3), 92-97.

Prescott, E. C. and R. M. Townsend (1984a). General Competitive Analysis in an Economy with Private Information. International Economic Review 25(1), 1-20.

Prescott, E. C. and R. M. Townsend (1984b). Pareto Optima and Competitive Equilibria with Adverse Selection and Moral Hazard. Econometrica 52(1), 21-45.

Prescott, E. S. and R. M. Townsend (2006). Firms as Clubs in Walrasian Markets with Private Information. Journal of Political Economy 114(4), 644-671.

Sattinger, M. (1993). Assignment models of the distribution of earnings. Journal of economic literature, 831-880.

\section{A Competitive Competitive Equilibrium and Constrained Optimality for Prototypical Economies}

\section{A.1 Competitive Equilibrium and Constrained Optimality for the Collateral Economy}

We can now write an agent of type $h$ 's utility maximization problem as follows: 


\section{Program 4.}

$$
\max _{y_{20}^{h}, \theta_{10}^{h}, \theta_{20}^{h}, \theta_{1 s}^{h}, \theta_{2 s}^{h}} u^{h}\left(c_{10}^{h}, c_{20}^{h}\right)+\beta \sum_{s=1}^{S} \pi_{s} u^{h}\left(c_{1 s}^{h}, c_{2 s}^{h}\right)
$$

subject to the budget constraint:

$$
\sum_{k=1}^{2} P_{k 0} \theta_{k 0}^{h}+\sum_{k=1}^{2} \sum_{s=1}^{S} P_{k s} \theta_{k s}^{h} \leq 0
$$

the production constraints (3), the consumption-relationship constraints (18), and the collateral constraints at $t=0(30)$, taking prices $\left(P_{k 0}, P_{k s}\right)$ as given.

There is no need to explicitly write down the profit maximization for the representative financial intermediary in this economy because there is no bundling in this economy, and therefore net supply of each security must be zero, i.e., $\psi_{j}=0$. As a result, the market clearing constraints for securities are as follows:

$$
\begin{aligned}
\sum_{h} \alpha^{h} \theta_{k 0}^{h} & =0, \text { for } k=1,2 \\
\sum_{h} \alpha^{h} \theta_{k s}^{h} & =0, \text { for } k=1,2 ; s=1, \ldots, S
\end{aligned}
$$

Definition 5. A competitive collateral equilibrium is a specification of allocation $\left(\mathbf{c}^{h}, \theta^{h}, \mathbf{y}^{h}\right)$ and prices $\left(P_{k 0}, P_{k s}\right)$ such that

(i) for each $h,\left(\mathbf{c}^{h}, \theta^{h}, \mathbf{y}^{h}\right)$ solves the utility maximization problem, Program (4), taking prices $\left(P_{k 0}, P_{k s}\right)$ as given;

(ii) markets for securities clear; 103 and 104 hold.

To be more specific, we further assume that preferences are identically homothetic as in Kilenthong and Townsend (2014b). The identically homothetic assumption gives us a strong, special version of (59); namely it implies that if there were the spot price $\tilde{p}_{s}$ in this economy, it would be a function of the aggregate (pre-trade but post storage/collateral decisions) ratio of good 1 to good 2 in state $s$ as follows:

$$
\tilde{p}_{s}=p\left(\frac{\sum_{h} \alpha^{h} e_{1 s}^{h}}{\sum_{h} \alpha^{h}\left(e_{2 s}^{h}-R_{s} y_{20}^{h}\right)}\right), \forall s
$$


That is, the market fundamental in this case is the pretrade aggregate ratio of good 1 to good 2. This functional relationship of the spot price plays a crucial role in generating externalities in this economy, and it translates in the obvious way to security prices $\mathbf{P}$, a special version of 60 , since trades of one good for the other in securities must clear, i.e.,

$$
\frac{P_{2 s}}{P_{1 s}}=\tilde{p}_{s} \Rightarrow P_{2 s}=p\left(\frac{\sum_{h} \alpha^{h} e_{1 s}^{h}}{\sum_{h} \alpha^{h}\left(e_{2 s}^{h}-R_{s} y_{20}^{h}\right)}\right) P_{1 s}, \forall s
$$

Crucially, these spot prices depend on agents' choices of collateral collectively. If aggregate collateral were not endogenous (see, e.g., Araujo et al., 2012), there would have been no price externalities in this model. This is because we have complete contracts in this model in contrast to the exogenous incomplete markets structure as in, e.g., Geanakoplos (2009); Greenwald and Stiglitz (1986).

The social planner's problem in this economy is as follows:

\section{Program 5.}

$$
\max _{\left(y_{20}^{h}, \theta_{10}^{h}, \theta_{20}^{h}, \theta_{1 s}^{h}, \theta_{2 s}^{h}\right)_{h}} u^{1}\left(c_{10}^{1}, c_{20}^{1}\right)+\beta \sum_{s} \pi_{s} u^{1}\left(c_{1 s}^{1}, c_{2 s}^{1}\right)
$$

subject to the participation constraints:

$$
u^{h}\left(c_{10}^{h}, c_{20}^{h}\right)+\beta \sum_{s=1}^{S} \pi_{s} u^{h}\left(c_{1 s}^{h}, c_{2 s}^{h}\right) \geq \overline{\mathscr{U}}^{h}, \text { for } h=2, \ldots, H,
$$

the production constraints (3), the consumption-relationship constraints (18), the collateral constraints at $t=0(30)$, the resource constraints (103)-(104), and the consistency constraints (106).

\section{A.2 Competitive Equilibrium and Constrained Optimality for the Exogenous Incomplete Markets Economy}

An individual maximization problem is as the following program:

\section{Program 6.}

$$
\max _{\theta_{10}^{h}, \theta_{20}^{h}, \theta_{j}^{h}, \tau_{1 s}^{h}, \tau_{2 s}^{h}} u^{h}\left(c_{10}^{h}, c_{20}^{h}\right)+\beta \sum_{s} \pi_{s} u^{h}\left(c_{1 s}^{h}, c_{2 s}^{h}\right)
$$


subject to the budget constraints in the first period,

$$
\theta_{10}^{h}+p_{0} \theta_{20}^{h}+\sum_{j=1}^{J} P_{j} \theta_{j}^{h} \leq 0,
$$

the consumption-relationship constraints (19)-(21), and the obstacle-to-trade constraints (31), taking prices $\left(P_{20}, P_{j}, \tilde{p}_{s}\right)$ as given.

Similarly to the collateral economy, there is no need to explicitly write down the profit maximization for the representative financial intermediary in this economy because there is no bundling in this economy, and therefore net supply of each security must be zero, i.e., $\psi_{j}=0$. As a result, the market clearing constraints for securities are as follows:

$$
\begin{aligned}
\sum_{h} \alpha^{h} \theta_{k 0}^{h} & =0, \text { for } k=1,2, \\
\sum_{h} \alpha^{h} \theta_{j}^{h} & =0, \text { for } j=1, \ldots, J \\
\sum_{h} \alpha^{h} \tau_{\ell s}^{h} & =0, \text { for } \ell=1,2 ; s=1, \ldots, S .
\end{aligned}
$$

Definition 6. A competitive equilibrium with exogenous security markets is a specification of allocation $\left(\mathbf{c}^{h}, \theta^{h}, \tau^{h}, \mathbf{y}^{h}\right)$ and prices $\left(P_{20}, P_{j}, \tilde{p}_{s}\right)$ such that

(i) for each $h,\left(\mathbf{c}^{h}, \theta^{h}, \tau^{h}, \mathbf{y}^{h}\right)$ solves the utility maximization problem, Program $(6)$, taking prices $\left(P_{20}, P_{j}, \tilde{p}_{s}\right)$ as given;

(ii) markets for securities and for spot trades clear; 111)-113 hold.

As in the general model, the social planner's problem takes into account the fact that the spot-market-clearing price in state $s, \tilde{p}_{s}$, is a function of agents' choices of ex-ante securities, i.e.,

$$
\tilde{p}_{s}=\tilde{p}_{s}(\theta, \mathbf{e}), \text { for } s=1, \ldots, S,
$$

where $\theta=\left(\theta^{1}, \ldots, \theta^{H}\right)$. These constitute the consistency constraints in this model. The social planner's problem in this economy is as follows:

\section{Program 7.}

$$
\max _{\left(\theta_{10}^{h}, \theta_{20}^{h}, \theta_{j}^{h}, \tau_{1 s}^{h}, \tau_{2 s}^{h}\right)_{h}} u^{1}\left(c_{10}^{1}, c_{20}^{1}\right)+\beta \sum_{s} \pi_{s} u^{1}\left(c_{1 s}^{1}, c_{2 s}^{1}\right)
$$


subject to the participation constraints,

$$
u^{h}\left(c_{10}^{h}, c_{20}^{h}\right)+\beta \sum_{s} \pi_{s} u^{h}\left(c_{1 s}^{h}, c_{2 s}^{h}\right) \geq \overline{\mathscr{U}}^{h}, \text { for } h=2, \ldots, H,
$$

the consumption-relationship constraints (19)-(21), and the obstacle-to-trade constraints (31), the resource constraints (111)-(113), and the consistency constraints (114).

The obstacle-to-trade or spot-budget constraints (31) can cause an inefficiency in this economy when the spot-market-clearing price in each state $s$ is a function of agents' choices of ex-ante securities, i.e., $\tilde{p}_{s}=\tilde{p}_{s}(\theta, \mathbf{e})$, and the security markets are incomplete. As in Geanakoplos and Polemarchakis (1986), the dependency generates an indirect price effect from security reallocations because the spot-market-clearing price is a function of agents' choices of securities. This indirect effect then produces an externality when the security markets are incomplete. On the other hand, when the security markets are complete, these indirect price effects are canceling each other out, and as a result, the competitive equilibrium with exogenous security markets is (constrained) efficient as expected. This statement is formally proved in the proposition below.

Proposition 1. The competitive equilibrium with exogenous security markets is (constrained) efficient if and only if the equilibrium allocation $\left(\mathbf{c}^{h}, \theta^{h}, \tau^{h}, \mathbf{y}^{h}\right)$ is first-best optimal or the spot price is independent of security positions, i.e., $\frac{\partial \tilde{p}_{s}}{\partial \theta_{j}^{h}}=0$ for every state s, every security $j$ and every agent of type $h$.

Proof. We begin the proof by deriving the necessary and sufficient conditions for the firstbest optimality. The social planner's problem for the first-best optimality is as follows:

\section{Program 8.}

$$
\max _{\left(\theta_{i 0}^{h}, \theta_{i s}^{h}\right)_{i, s, h}} u^{1}\left(e_{10}^{1}+\theta_{10}^{1}, e_{20}^{1}+\theta_{20}^{1}\right)+\beta \sum_{s} \pi_{s} u^{1}\left(e_{1 s}^{1}+\theta_{1 s}^{1}, e_{2 s}^{1}+\theta_{2 s}^{1}\right)
$$

subject to the participation constraints and the resource constraints, respectively,

$$
\begin{aligned}
u^{h}\left(e_{10}^{h}+\theta_{10}^{h}, e_{20}^{h}+\theta_{20}^{h}\right)+\beta \sum_{s} \pi_{s} u^{h}\left(e_{1 s}^{h}+\theta_{1 s}^{h}, e_{2 s}^{h}+\theta_{2 s}^{h}\right) & \geq \overline{\mathscr{U}}^{h}, \text { for } h=2, \ldots, H \\
\sum_{h} \alpha^{h} \theta_{i s}^{h} & =0, \text { for } i=1,2 ; s=0,1, \ldots, S
\end{aligned}
$$


Lemma 1. The necessary and sufficient conditions for the first-best optimality are as follows:

$$
\begin{aligned}
\frac{\gamma_{u}^{h} u_{i 0}^{h}}{\alpha^{h}} & =\frac{\gamma_{u}^{\tilde{h}} u_{i 0}^{\tilde{h}}}{\alpha^{\tilde{h}}}, \forall h, \tilde{h}=1, \ldots, H ; i=1,2 \\
\frac{\gamma_{u}^{h} \beta \pi_{s} u_{i s}^{h}}{\alpha^{h}} & =\frac{\gamma_{u}^{\tilde{h}} \beta \pi_{s} u_{i s}^{\tilde{h}}}{\alpha^{\tilde{h}}}, \forall h, \tilde{h}=1, \ldots, H ; i=1,2, s=1, \ldots, S,
\end{aligned}
$$

where $\gamma_{u}^{h}$ is the Lagrange multipliers for the participation constraints for $h$ (normalize by setting $\left.\gamma_{u}^{1}=1\right)$ and $u_{i s}^{h}=\frac{\partial u^{h}}{\partial c_{i s}^{h}}$ is the marginal utility of an agent of type $h$ with respect to $c_{i s}$.

We now consider the following social planner's problem for the economy with exogenous security markets.

\section{Program 9.}

$$
\max _{\left(\theta_{10}^{h}, \theta_{20}^{h}, \theta_{j}^{h}, \tau_{1 s}^{h}, \tau_{2 s}^{h}\right)_{h}} u^{1}\left(e_{10}^{1}+\theta_{10}^{1}, e_{20}^{1}+\theta_{20}^{1}\right)+\beta \sum_{s} \pi_{s} u^{1}\left(e_{1 s}^{1}+\theta_{s}^{1}+\tau_{1 s}^{1}, e_{2 s}^{1}+\tau_{2 s}^{1}\right)
$$

subject to the participation constraints, the resource constraints, and the obstacle-to-trade constraints, respectively,

$$
\begin{aligned}
& u^{h}\left(e_{10}^{h}+\theta_{10}^{h}, e_{20}^{h}+\theta_{20}^{h}\right)+\beta \sum_{s} \pi_{s} u^{h}\left(e_{1 s}^{h}+\sum_{j} D_{j s} \theta_{j}^{h}+\tau_{1 s}^{h}, e_{2 s}^{h}+\tau_{2 s}^{h}\right) \geq \overline{\mathscr{U}}^{h}, \text { for } h=2, . \\
& \sum_{h} \alpha^{h} \theta_{i 0}^{h}=0, \text { for } i=1,2, \\
& \sum_{h} \alpha^{h} \theta_{j}^{h}=0, \text { for } j=1, \ldots, \\
& \sum_{h} \alpha^{h} \tau_{1 s}^{h}=0, \text { for } s=1, \ldots, \\
& \tau_{1 s}^{h}+\tilde{p}_{s}\left(\theta_{s}^{1}, \ldots, \theta_{s}^{H}\right) \tau_{2 s}^{h}=0, \text { for } s, h .
\end{aligned}
$$

Note that the resource (market-clearing) constraints for $\tau_{2 s}^{h}$ are omitted due to Walras law. A solution to this social planner's problem is called a constrained optimal allocation.

The first order conditions for $\theta_{10}^{h}, \theta_{20}^{h}, \tau_{1 s}^{h}, \tau_{2 s}^{h}, \theta_{j}^{h}$ are as follows:

$$
\begin{aligned}
\gamma_{u}^{h} \beta \pi_{s} u_{10}^{h}+\alpha^{h} \mu_{10}^{\theta} & =0, \\
\gamma_{u}^{h} \beta \pi_{s} u_{20}^{h}+\alpha^{h} \mu_{20}^{\theta} & =0, \\
\gamma_{u}^{h} \beta \pi_{s} u_{1 s}^{h}+\alpha^{h} \mu_{1 s}^{\tau}+\gamma_{s}^{h} & =0, \forall s=1, \ldots, S, \\
\gamma_{u}^{h} \beta \pi_{s} u_{2 s}^{h}+\tilde{p}_{s} \gamma_{s}^{h} & =0, \forall s=1, \ldots, S, \\
\gamma_{u}^{h} \beta \sum_{s} \pi_{s} u_{1 s}^{h} D_{j s}+\alpha^{h} \mu_{j}^{\theta}+\sum_{s} \frac{\partial \tilde{p}_{s}}{\partial \theta_{j}^{h}} \sum_{\tilde{h}} \gamma_{s}^{\tilde{h}} \tau_{2 s}^{\tilde{h}} & =0, \forall j=1, \ldots, J,
\end{aligned}
$$


where $\gamma_{s}^{h}, \gamma_{s}^{h}, \mu_{s}^{\tau}, \mu_{j}^{\theta}$ are the Lagrange multipliers for the obstacle to trade or spot-market constraints in state $s$, for the participation constraints for $h$ (normalize by setting $\gamma_{u}^{1}=1$ ), for the resource constraints for $\tau_{1 s}^{h}$, and for the resource constraints for $\theta_{j}^{h}$. Note that $u_{i s}^{h}=\frac{\partial u^{h}}{\partial c_{i s}^{h}}$.

The proof is divided into two parts as follows:

(i) $(\Leftarrow)$ We now show that an allocation that satisfies the necessary and sufficient conditions for the first-best optimality (118)-(119) must satisfies the first order conditions 126)-130. It is not difficult to see that this will be the case if the externality term, the last term of 130 , is vanished, i.e.,

$$
\sum_{s} \frac{\partial \tilde{p}_{s}}{\partial \theta_{j}^{h}} \sum_{\tilde{h}} \gamma_{s}^{\tilde{h}} \tau_{2 s}^{\tilde{h}}=0
$$

It is obvious that if the spot price is independent of security positions, i.e., $\frac{\partial \tilde{p}_{s}}{\partial \theta_{j}^{h}}=0$ for every state $s$, every security $j$ and every agent of type $h$, then condition (131) holds.

We now need to show that if the constrained optimal allocation is first-best optimal, then the no-externality condition (131) must hold. Since the allocation is first- best optimal, it must satisfies conditions 118 and 119 , which imply that $\left(\frac{\gamma_{s}^{\tilde{h}}}{\alpha^{\tilde{h}}}\right)$ must be constant across agents, i..e, for each $s$

$$
\frac{\gamma_{s}^{h}}{\alpha^{h}}=\frac{\gamma_{s}^{\tilde{h}}}{\alpha^{\tilde{h}}}=\Gamma_{s}, \forall h, \tilde{h} .
$$

Using these conditions, we can then show that

$$
\begin{aligned}
\sum_{s} \frac{\partial \tilde{p}_{s}}{\partial \theta_{j}^{h}} \sum_{\tilde{h}} \gamma_{s}^{\tilde{h}} \tau_{2 s}^{\tilde{h}} & =\sum_{s} \frac{\partial \tilde{p}_{s}}{\partial \theta_{j}^{h}} \sum_{\tilde{h}}\left(\frac{\gamma_{s}^{\tilde{h}}}{\alpha^{\tilde{h}}}\right) \alpha^{\tilde{h}} \tau_{2 s}^{\tilde{h}} \\
& =\sum_{s} \frac{\partial \tilde{p}_{s}}{\partial \theta_{j}^{h}} \sum_{\tilde{h}} \Gamma_{s} \alpha^{\tilde{h}} \tau_{2 s}^{\tilde{h}}=\sum_{s} \frac{\partial \tilde{p}_{s}}{\partial \theta_{j}^{h}} \Gamma_{s} \sum_{\tilde{h}} \alpha^{\tilde{h}} \tau_{2 s}^{\tilde{h}}=0
\end{aligned}
$$

where the last equation results from the resource constraints for $\tau_{2 s}^{h}$. This proves that the no-externality condition (131) holds. To sum up, we prove that there is no externality if the constrained optimal allocation is first-best optimal or the spot price is independent of security positions, i.e., $\frac{\partial \tilde{p}_{s}}{\partial \theta_{j}^{h}}=0$ for every state $s$, every security $j$ and every agent of type $h$. 
(ii) $(\Rightarrow)$ Unfortunately, we cannot generally prove the reversed statement but, as shown in Geanakoplos and Polemarchakis (1986), it is true generically (it is true except for some unlikely cases). The key idea is that the indirect price effects could be canceling each other out only if the equilibrium allocation is first-best optimal in most cases. But this does not happen generally.

\section{A.3 Competitive Equilibrium and Constrained Optimality for the Moral Hazard with Retrading Economy}

An individual problem can be written as a two-step problem. The first step is to maximizing utility subject to budget, consumption relationship, and production constraints, conditional on taken action $a$ and incentive compatibility constraints which make that the actual action coincides with the recommended action, $a^{\prime}=a$, as follow:

\section{Program 10.}

$$
\max _{a, \theta_{k}(\mathbf{q}, a)} \sum_{\mathbf{q}} \pi(\mathbf{q} \mid a) u\left(c_{1}(\mathbf{q}, a), c_{2}(\mathbf{q}, a), a\right)
$$

subject to the budget constraints

$$
\sum_{\mathbf{q}} \sum_{k} P_{k}(\mathbf{q}, a) \theta_{k}(\mathbf{q}, a) \leq 0, \forall a
$$

the production constraints (7), the consumption-relationship constraints (22), and the incentive compatibility constraints (34), taking as given the security prices $P_{k}(\mathbf{q}, a)$ and the spot price $\tilde{p}$ along the equilibrium path $a=a^{\prime}$.

There is a representative financial intermediary who chooses net supply of securities $\psi=\left[\psi_{k}(\mathbf{q}, a)\right]_{\mathbf{q}, k, a}$ to maximize profit

$$
\max _{\psi} \sum_{\mathbf{q}} \sum_{k} \sum_{a} P_{k}(\mathbf{q}, a) f(\mathbf{q} \mid a) \psi_{k}(\mathbf{q}, a)
$$

subject to feasibility constraints

$$
\sum_{\mathbf{q}} f(\mathbf{q} \mid a) \psi_{k}(\mathbf{q}, a)=0, \forall a ; k=1,2
$$


That is, there are $M=2 A$ conditions in 138 and the security weight matrix is a $2 \times 2 Q A$ dimensional matrix $\Psi=I_{2 A} \otimes 1_{Q}$, where $I_{2 A}$ is the identity matrix with dimension $2 A, 1_{Q}$ is the row of ones with dimension $Q$, and $\otimes$ is the Kronecker product operator. Similarly, the eligibility weights $\xi_{j}=\xi_{k}(\mathbf{q}, a)=f(\mathbf{q} \mid a)$. Note that $j$ is indexed by $(\mathbf{q}, k, a)^{10}$

The existence of a maximum to the problem requires that

$$
P_{k}(\mathbf{q}, a)=\mu_{k}(a), \forall \mathbf{q} ; a ; k=1,2
$$

where $\mu_{k}(a)$ is the Lagrange multiplier with respect to the feasibility constraint (138) for a bundle $(k, a)$. This clearly implies zero profit for each financial intermediary, and therefore there is no loss of generality to assume there is one representative financial intermediary for each $a$.

The market clearing conditions for securities are as follows:

$$
\theta_{k}(\mathbf{q}, a)=\psi_{k}(\mathbf{q}, a), \forall \mathbf{q}, a ; k=1,2
$$

Substituting the market clearing conditions (140) into the (binding) feasibility constraints

\footnotetext{
${ }^{10} \mathrm{~A}$ typical vector of securities is

$$
\psi=\left(\psi_{1}\left(\mathbf{q}_{1}, a_{1}\right), \ldots, \psi_{1}\left(\mathbf{q}_{Q}, a_{1}\right), \ldots, \psi_{1}\left(\mathbf{q}_{Q}, a_{A}\right), \psi_{2}\left(\mathbf{q}_{1}, a_{1}\right), \ldots, \psi_{2}\left(\mathbf{q}_{Q}, a_{A}\right)\right) .
$$
}

For example, with $A=\left\{a_{1}, a_{2}\right\}$ and $Q=\left(\mathbf{q}_{1}, \mathbf{q}_{2}\right)$, the dimension of the vector of securities is $J=2 Q A=8$; that is,

$$
\psi=\left(\psi_{1}\left(\mathbf{q}_{1}, a_{1}\right), \psi_{1}\left(\mathbf{q}_{2}, a_{1}\right), \psi_{1}\left(\mathbf{q}_{1}, a_{2}\right), \psi_{1}\left(\mathbf{q}_{2}, a_{2}\right), \psi_{2}\left(\mathbf{q}_{1}, a_{1}\right), \psi_{2}\left(\mathbf{q}_{2}, a_{1}\right), \psi_{2}\left(\mathbf{q}_{1}, a_{2}\right), \psi_{2}\left(\mathbf{q}_{2}, a_{2}\right)\right) .
$$

Accordingly, the eligibility weights are

$$
\xi=\left(f\left(\mathbf{q}_{1} \mid a_{1}\right), f\left(\mathbf{q}_{2} \mid a_{1}\right), f\left(\mathbf{q}_{1} \mid a_{2}\right), f\left(\mathbf{q}_{2} \mid a_{2}\right), f\left(\mathbf{q}_{1} \mid a_{1}\right), f\left(\mathbf{q}_{2} \mid a_{1}\right), f\left(\mathbf{q}_{1} \mid a_{2}\right), f\left(\mathbf{q}_{2} \mid a_{2}\right)\right) .
$$

The security weight matrix in this case is as follows:

$$
\Psi_{4 \times 8}=I_{4} \otimes 1_{2}=\left[\begin{array}{cccccccc}
1 & 1 & 0 & 0 & 0 & 0 & 0 & 0 \\
0 & 0 & 1 & 1 & 0 & 0 & 0 & 0 \\
0 & 0 & 0 & 0 & 1 & 1 & 0 & 0 \\
0 & 0 & 0 & 0 & 0 & 0 & 1 & 1
\end{array}\right] .
$$


(138) gives the following resource constraints.

$$
\sum_{\mathbf{q}} f(\mathbf{q} \mid a) \theta_{k}(\mathbf{q}, a)=0, \forall a ; k=1,2
$$

Definition 7. A competitive equilibrium with moral hazard and retrading is a specification of allocation $(\mathbf{c}, \theta, a)$ for households and $\psi$ for intermediaries, and prices $(\tilde{p}, \mathbf{P})$ such that

(i) for each household, $(\mathbf{c}, \theta, a)$ solves the utility maximization problem, Program (10), taking prices $(\tilde{p}, \mathbf{P})$ as given;

(ii) for the financial intermediary $a, \psi$ solves (137) subject to $(138)$, taking prices $\mathbf{P}$ as given;

(iii) markets for securities clear; 140 hold.

As in the general model, the social planner's problem takes into account the fact that the spot-market-clearing price $\tilde{p}$ depends on the choice of contracts $\theta_{a}=\left[\theta_{k}(\mathbf{q}, a)\right]_{k, \mathbf{q}}$ and actual action $a$; that is, $\tilde{p}=\tilde{p}\left(\theta_{a}, a\right)$. Recall that the spot price $\tilde{p}$ clears the spot markets; that is,

$$
\sum_{\mathbf{q}, a} \delta(a) f(\mathbf{q} \mid a) \tau_{k}(\mathbf{q}, a)=0
$$

where $\tau_{k}(\mathbf{q}, a)$ be equilibrium spot trade of an agent of ex-post type $(\mathbf{q}, a)$, which is the solution to problem when $a$ is both the recommended and taken action. We do not include these conditions as resource constraints since they are redundant as discussed earlier in Section 2.2.3.

The resource constraints are as follows:

$$
\sum_{\mathbf{q}} f(\mathbf{q} \mid a) \theta_{k}(\mathbf{q}, a) \leq 0, \forall a ; k=1,2
$$

Note that the planner also takes into account that the choice of contracts must be consistent with actual action on the equilibrium path; that is, $\theta_{k}(\mathbf{q}, a)$ depends on recommended and actual action $a$. To sum up, the consistency constraint is as follows:

$$
\tilde{p}=\tilde{p}\left(\theta_{a}, a\right)
$$

The social planner's problem is to choose contracts that solves the following program. 


\section{Program 11.}

$$
\max _{a, \theta_{k}(\mathbf{q}, a)} \sum_{\mathbf{q}} \pi(\mathbf{q} \mid a) u\left(c_{1}(\mathbf{q}), c_{2}(\mathbf{q}), a\right)
$$

subject to the production constraints (7), the consumption-relationship constraints (22), the incentive compatibility constraints (34), the resource constraints (143), and the consistency constraints (144).

\section{A.4 Competitive Equilibrium and Constrained Optimality for the Liquidity Constrained Economy}

An individual maximization problem for an agent type $h=b, d$ is as the following program:

\section{Program 12.}

$$
\max _{\left(f_{0}^{h}, l^{h}, \tau_{b}^{h}, \tau_{d}^{h}, \tau_{f t}^{h}\right)} w_{3}^{h}+\delta_{b}^{h} b^{h}+\left(1-\delta_{d}^{h}\right) d^{h}-\frac{\left(l^{h}\right)^{2}}{2}
$$

subject to the production constraints (12)-(15), the consumption-relationship constraints (23)-(26), and the obstacle-to-trade constraints (36)-37), taking prices $\left(p_{b}, p_{d}\right)$ as given.

Similarly to the collateral economy, there is no need to explicitly write down the profit maximization for the representative financial intermediary in this economy because there is no bundling in this economy.

The market clearing constraints for spot trades are as follows:

$$
\sum_{h} \alpha^{h} \tau_{\ell}^{h}=0, \text { for } \ell=f 1, f 2, b, d
$$

Definition 8. A competitive equilibrium with liquidity constraints is a specification of allocation $\left(f_{0}^{h}, l^{h}, \tau_{b}^{h}, \tau_{d}^{h}, \tau_{f t}^{h}, b^{h}, d^{h}, w_{3}^{h}, \mathbf{y}\right)$ and prices $\left(\tilde{p}_{b}, \tilde{p}_{d}\right)$ such that

(i) for each $h,\left(f_{0}^{h}, l^{h}, \tau_{b}^{h}, \tau_{d}^{h}, \tau_{f t}^{h}\right)$ solves the utility maximization problem, Program (12), taking prices $\left(\tilde{p}_{b}, \tilde{p}_{d}\right)$ as given;

(ii) markets for spot trades clear; 147 hold. 
As in the general model, the social planner's problem takes into account the fact that the spot-market-clearing prices $\tilde{p}_{b}$ and $\tilde{p}_{d}$ are functions of agents' choices of storage in period $t=0$ and $t=1$, respectively, i.e., $\tilde{p}_{b}=p_{b}\left(f_{0}^{b}, f_{0}^{d}\right)$ and $\tilde{p}_{d}=p_{d}\left(f_{1}^{b}, f_{1}^{d}\right)$. For example, in Hart and Zingales (2113), $\tilde{p}_{b}=f^{\frac{1}{2}}$ and $\tilde{p}_{d}=f^{\frac{3}{4}}$, where $f_{0}^{b}=0$ and $f_{0}^{d}=f$. These constitute the consistency constraints in this model as follows:

$$
\begin{aligned}
& \tilde{p}_{b}=p_{b}\left(f_{0}^{b}, f_{0}^{d}\right) \\
& \tilde{p}_{d}=p_{d}\left(f_{1}^{b}, f_{1}^{d}\right)
\end{aligned}
$$

The social planner's problem in this economy is as follows:

\section{Program 13.}

$$
\max _{\left(f_{0}^{h}, l^{h}, \tau_{b}^{h}, \tau_{d}^{h}, \tau_{f t}^{h}\right)_{h}} w_{3}^{b}+d^{b}-\frac{\left(l^{b}\right)^{2}}{2}
$$

subject to the production constraints (12)-(15), the consumption-relationship constraints (23)- 26), and the obstacle-to-trade constraints (36)-(37), and the consistency constraints (148)- 149 .

\section{B More Prototypical Economies}

\section{B.1 Fire Sales Economy (Lorenzoni, 2008)}

\section{B.1.1 Basic Ingredients for the Fire Sales Economy}

Consider an economy with three periods, $t=0,1,2$. There are two states, $s=1,2$, realized in period $t=1$, with probability $\pi_{1}$ and $\pi_{2}$, respectively. We use histories of these states to define states in period $t=2$; that is, if the state $s=1$ is realized in period $t=1$, then the state in period $t=2$ will automatically be $s=1$. Therefore, there are two states $s=1,2$ in the last period $t=2$. There are two types of agents, called "consumers" and "entrepreneurs", each of which consists of equal mass. A consumer receives an endowment of $e$ units of consumption goods in each period while an entrepreneur is endowed with $n$ units of consumption goods in the first period $t=0$ only. 
There are $L=8$ commodities in this model, i.e., two physical goods, namely consumption and capital goods, in period $t=0$, two physical goods, namely consumption and capital goods, at each state $s=1,2$ in period $t=1$, and one physical good, namely consumption good, at each state $s=1,2$ in period $t=2$.

The preferences of a consumer is represented by

$$
U^{c}(\mathbf{c})=E\left[c_{0}^{c}+c_{1}^{c}+c_{2}^{c}\right]=c_{0}^{c}+\sum_{s=1,2} \pi_{s}\left(c_{1 s}^{c}+c_{2 s}^{c}\right)
$$

where superscript "c" stands for consumer, $c_{0}^{c}$ is the consumer's consumption in period 0 , and $c_{t s}^{c}$ is the consumer's consumption at state $s=1,2$ in period $t=1,2$. The preferences of an entrepreneur is represented by

$$
U^{e}(\mathbf{c})=E\left[c_{2}^{e}\right]=\sum_{s=1,2} \pi_{s} c_{2 s}^{e}
$$

where superscript "e" stands for entrepreneur, $c_{2 s}^{e}$ is the entrepreneur's consumption at state $s=1,2$ in period $t=2$.

The following production functions, and inputs/outputs are generally written as $F_{\ell t s}^{h}$, and $y_{\ell t s}^{h}$, where $h=c, e$ denotes an agent type, $\ell=c, i, k, n, o, p, r$ denotes an input/output type of commodities ( "c" stands for consumption goods, "i" stands for input for new capital production, "k" stands for capital input, "n" stands for new capital, "o" stands for old capital, "r" stands for repairing input for capital maintenance) or a constraint type ("p" stands for weakly positive constraints), $t=0,1,2$ denotes a period, and $s=0,1,2$ denotes a state with state $s=0$ for period $t=0$.

Each entrepreneur can turn a unit of consumption good into a unit of (new) capital good at any period and any state of nature. This constitutes the first set of production functions:

$$
\begin{aligned}
& F_{n 00}^{e}\left(y_{n 00}^{e}, y_{i 00}^{e}\right)=y_{n 00}^{e}+y_{i 00}^{e}=0 \\
& F_{n 1 s}^{e}\left(y_{n 1 s}^{e}, y_{i 1 s}^{e}\right)=y_{n 1 s}^{e}+y_{i 1 s}^{e}=0, \forall s=1,2
\end{aligned}
$$

where $y_{n 00}^{e} \in \mathbb{R}_{+}\left(y_{i 00}^{e} \in \mathbb{R}_{-}\right)$and $y_{n 1 s}^{e} \in \mathbb{R}_{+}\left(y_{i 1 s}^{e} \in \mathbb{R}_{-}\right)$are the outputs in unit of capital goods (inputs in unit of consumption goods) in period $t=0$, and at state $s$ in period $t=1$, respectively. These specifications with profit maximization limit the price of capital not to be larger than 1 at any point in time. On the other hand, the capital investment is 
irreversible; that is, it is not feasible to directly turn a capital good into consumption goods. This irreversibility leads to fire sales, which can cause the price of capital to be significantly below one.

In addition, each entrepreneur has access to an entrepreneurial production technology, which transforms $y_{n 00}^{e}$ units of the capital goods in period $t=0$ into $a_{s} y_{n 00}^{e}$ units of the consumption goods in period $t=1$, where $s=1,2$ is the aggregate state. This technology can be represented by the following production function:

$$
F_{c 1 s}^{e}\left(y_{c 1 s}^{e}, y_{n 00}^{e}\right)=y_{c 1 s}^{e}-a_{s} y_{n 00}^{e}=0, \forall s=1,2,
$$

where $y_{c 1 s}^{e}$ is the output in unit of consumption goods at state $s=1,2$ in period $t=1$.

The capital must be repaired at the $\operatorname{cost} \gamma>0$ units of consumption goods at state $s=1,2$ in period $t=1$ per unit of capital chosen to be repaired. Non-repaired part will be fully depreciated. This maintenance technology can be represented by the following production function:

$$
F_{r 1 s}^{e}\left(y_{o 1 s}^{e}, y_{r 1 s}^{e}\right)=\gamma y_{o 1 s}^{e}+y_{r 1 s}^{e}=0, \forall s=1,2
$$

where $y_{o 1 s}^{e} \in \mathbb{R}_{+}$is the output in unit of (old) capital goods at state $s$ in period $t=1$ from this maintenance process, and $y_{r 1 s}^{e} \in \mathbb{R}_{-}$is the input in unit of consumption goods for the maintenance process. The production technology also requires that old repaired capital cannot be larger (in absolute value) than the original capital from period $t=0$, i.e.,

$$
F_{p 1 s}^{e}\left(y_{o 1 s}^{e}, y_{r 1 s}^{e}\right)=y_{o 1 s}^{e}+y_{r 1 s}^{e} \geq 0, \forall s=1,2
$$

Further, an entrepreneur can use all capital available in period $t=1, y_{k 1 s}^{e}$, to produce $A y_{k 1 s}^{e}$ units of consumption goods in period $t=2$, with $A>1$. This technology can be represented by the following production function:

$$
F_{c 2 s}^{e}\left(y_{c 2 s}^{e}, y_{k 1 s}^{e}\right)=y_{c 2 s}^{e}-A y_{k 1 s}^{e}=0, \forall s=1,2
$$

where $y_{c 2 s}^{e}$ is the output in unit of consumption goods at state $s=1,2$ in period $t=1$.

Each consumer owns a traditional production technology, which produces consumption goods in period $t=2$ using capital goods in period $t=1, y_{k 1 s}^{c}$, as the input. The traditional technology is represented by the production function $f\left(y_{k 1 s}^{c}\right)$, which is assumed to 
be increasing, strictly concave, twice differentiable, and satisfies the following properties $f(0)=0, f^{\prime}(0)=1, f^{\prime}\left(y_{1 s}^{c}\right) \geq \bar{q}$. Strict concavity and $f^{\prime}(0)=1$ assumptions imply that

consumers would not produced (new) capital using technology (153)-(154) even if they were be able to do so. They will own capital only when there is fire sales, under which the price of capital wold be below one. The capital good is fully depreciated at the end of the last period $t=2$. This traditional technology can be represented by the following production function:

$$
F_{c 2 s}^{c}\left(y_{c 2 s}^{c}, y_{k 1 s}^{c}\right)=y_{c 2 s}^{c}-f\left(y_{k 1 s}^{c}\right)=0, \forall s=1,2,
$$

where $y_{c 2 s}^{c}$ is the output in unit of consumption goods in period $t=2$.

To sum up, there are $O=13$ production functions in this model.

\section{B.1.2 Market Structure the Fire Sales Economy}

Let $\theta_{0}^{h}$ and $\theta_{t s}^{h}$ denote securities paying in unit of consumption goods in period $t=0$, and securities paying in consumption goods at state $s=1,2$ in period $t=1,2$ acquired by an agent type $h=c, e$, respectively. There are $J=5$ securities. Let $P_{t s}$ denote the security price of a security paying in consumption goods at state $s=1,2$ in period $t=1,2$, and $P_{0}=1$ the price of the security paying in unit of consumption goods in period $t=0$, which is the numeraire good.

There are also spot markets at each state $s=1,2$ in period $t=1$. There are $L^{s}=2$ commodities in each spot markets. We set the spot-market-clearing price of good 1 equal to one (the numeraire good), and let $p_{s}$ denote the spot-market-clearing price of good 2. As in Lorenzoni (2008), the market clearing conditions for the spot markets in each state $s$ (for $\tau_{k s}^{h}$ and $\left.\tau_{c s}^{h}\right)$ imply that the spot price $\tilde{p}_{s}$ is determined by capital input for the traditional technology $y_{k 1 s}^{c}$, i.e., $\tilde{p}_{s}=f^{\prime}\left(y_{k 1 s}^{c}\right)$. 
The consumption-relationship functions for consumers and entrepreneurs are given by

$$
\begin{aligned}
g_{c 0}^{c}\left(e, \theta_{0}^{c}, c_{0}^{c}\right) & =e+\theta_{0}^{c}-c_{0}^{c}=0, \\
g_{c 1 s}^{c}\left(e, \theta_{1 s}^{c}, \tau_{c s}^{c}, c_{1 s}^{c}\right) & =e+\theta_{1 s}^{c}+\tau_{c s}^{c}-c_{1 s}^{c}=0, \forall s=1,2, \\
g_{c 2 s}^{c}\left(e, \theta_{2 s}^{c}, y_{c 2 s}^{c}, c_{2 s}^{c}\right) & =e+\theta_{2 s}^{c}+y_{c 2 s}^{c}-c_{2 s}^{c}=0, \forall s=1,2, \\
g_{k s}^{c}\left(\tau_{k s}^{c}, y_{k 1 s}^{c}\right) & =\tau_{k s}^{c}-y_{k 1 s}^{c}=0, \forall s=1,2, \\
g_{c 0}^{e}\left(n, \theta_{0}^{c}, y_{i 00}^{e}\right) & =n+\theta_{0}^{c}-y_{i 00}^{e}=0, \\
g_{c 1 s}^{e}\left(\theta_{1 s}^{e}, \tau_{c s}^{e}, y_{c 1 s}^{e}, y_{r 1 s}^{e}, y_{i 1 s}^{e}\right) & =\theta_{1 s}^{e}+\tau_{c s}^{e}+y_{c 1 s}^{e}+y_{r 1 s}^{e}+y_{i 1 s}^{e}=0, \forall s=1,2, \\
g_{k s}^{e}\left(y_{n 1 s}^{e}, y_{o 1 s}^{e}, \tau_{k s}^{e}, y_{k 1 s}^{e}\right) & =y_{n 1 s}^{e}+y_{o 1 s}^{e}+\tau_{k s}^{e}-y_{k 1 s}^{e}=0, \forall s=1,2, \\
g_{c 2 s}^{e}\left(y_{c 2 s}^{e}, \theta_{2 s}^{e}, c_{2 s}^{e}\right) & =y_{c 2 s}^{e}+\theta_{2 s}^{e}-c_{2 s}^{e}=0, \forall s=1,2,
\end{aligned}
$$

where a function with superscript "c" ("e") is a consumption-relationship function for consumers (for entrepreneurs). There are $N=14$ consumption-relationship conditions.

\section{B.1.3 Trade Frictions for the Fire Sales Economy}

Each consumer faces the following sets of obstacle-to-trade constraints. First, the participation constraint for a consumer is given by

$$
C_{p c}^{c}\left(\theta_{0}^{c}, \theta_{1 s}^{c}, \theta_{2 s}^{c}\right)=\theta_{0}^{c}+\sum_{s} \pi_{s}\left(\theta_{1 s}^{c}+\theta_{2 s}^{c}\right) \geq 0 .
$$

This constraint states that a consumer would not enter the contract at period $t=0$ and would be at autarky unless the contract offers a non-negative expected return from $t=0$ to $t=2$. Second, the no-default conditions for a consumer are as follows:

$$
\begin{aligned}
C_{c d 1}^{c}\left(\theta_{1 s}^{c}, \theta_{2 s}^{c}\right) & =\theta_{1 s}^{c}+\theta_{2 s}^{c} \geq 0, \forall s=1,2, \\
C_{c d 2}^{c}\left(\theta_{2 s}^{c}\right) & =\theta_{2 s}^{c} \geq 0, \forall s=1,2 .
\end{aligned}
$$

These constraints imply that a consumer would default (not pay when $\theta_{t s}^{c}<0$ ) at state $s=1,2$ in period $t=1,2$ unless the return from that period on is non-negative.

Each entrepreneur faces the following obstacle-to-trade constraints or no-default conditions:

$$
\begin{aligned}
C_{e d 1}^{e}\left(y_{n 00}^{e}, \theta_{1 s}^{e}, \theta_{2 s}^{e}, \tilde{p}_{s}\right) & =\left(\eta a_{s}+\max \left\{\tilde{p}_{s}-\gamma, 0\right\}\right) y_{n 00}^{e}+\theta_{1 s}^{e}+\theta_{2 s}^{e} \geq 0, \forall s=1,2, \\
C_{e d 2}^{e}\left(y_{k 1 s}^{e}, \theta_{2 s}^{e}\right) & =\eta A y_{k 1 s}^{e}+\theta_{2 s}^{e} \geq 0, \forall s=1,2
\end{aligned}
$$


where $1-\eta \in(0,1)$ is the fraction of the firm's current profit that the entrepreneur could keep if he decided to default. Constraints 171 imply that the entrepreneur is better off not defaulting at state $s=1,2$ in period $t=1$. In particular, he would get $(1-\eta) a_{s} y_{n 00}^{e}$ if he defaulted. On the other hand, his net income would be $\left(a_{s}+\max \left\{\tilde{p}_{s}-\gamma, 0\right\}\right) y_{n 00}^{e}+\theta_{1 s}^{e}+\theta_{2 s}^{e}$ in case of no default. Similarly, constraints 172 imply that net income of the entrepreneur at state $s=1,2$ in period $t=2$ in case of no default, $A y_{k 1 s}^{e}+\theta_{2 s}^{e}$, is larger than his net income in case of default, $(1-\eta) A y_{k 1 s}^{e}$.

In addition, both agent types also face the following spot market budget constraints:

$$
C_{\text {spot }}^{h}\left(\tau_{c s}^{h}, \tau_{k s}^{h}, \tilde{p}_{s}\right)=\tau_{c s}^{h}+\tilde{p}_{s} \tau_{k s}^{h}=0, \forall h=c, e ; s=1,2
$$

To be consistent with the general model, there are $I=11$ sets of obstacle-to-trade constraints, each of which contains only one constraint, i.e., $A=1$. Therefore, there are $M=11$ obstacle-to-trade constraints in total.

It is worthy of emphasis that the spot market budget constraints (173) are not the sources of the externality here because this model has a complete contingent contracting structure. See a similar result in Proposition 1. On the other hand, the key obstacleto-trade constraints that cause an inefficiency in this model is the first set of no-default conditions for an entrepreneur (171), which again depends on equilibrium prices which in turn are determined by collective ex-ante choices of the agents.

\section{B.1.4 Competitive Equilibrium and Constrained Optimality for the Fire Sales Economy}

A consumer's maximization problem is as follows:

Program 14.

$$
\max _{\theta_{0}^{c}, \theta_{t s}^{c}, \tau_{c s}^{c}, \tau_{k s}^{c}} c_{0}^{c}+\sum_{s=1,2} \pi_{s}\left(c_{1 s}^{c}+c_{2 s}^{c}\right)
$$

subject to the budget constraints

$$
\theta_{0}^{c}+\sum_{s, t} P_{t s} \theta_{t s}^{c} \leq 0
$$


the production constraints (159), the consumption-relationship constraints (160)-(163), and the obstacle-to-trade constraints $168-(170),(173)$, taking prices $\left(P_{t s}, \tilde{p}_{s}\right)$ as given.

Similarly, the entrepreneur's maximization problem is given by

\section{Program 15.}

$$
\max _{\theta_{0}^{e}, \theta_{t s}^{e}, \tau_{c s}^{e}, \tau_{k s}^{e}, y_{i 0}^{n}, y_{i 1 s}^{n}, y_{i 1 s}^{o}} \sum_{s=1,2} \pi_{s} c_{2 s}^{e}
$$

subject to the budget constraints

$$
\theta_{0}^{e}+\sum_{s, t} P_{t s} \theta_{t s}^{e} \leq 0
$$

the production constraints (153)-(158), the consumption-relationship constraints (164)-(167), and the obstacle-to-trade constraints 1171 - 172 , 173), taking prices $\left(P_{t s}, \tilde{p}_{s}\right)$ as given.

Similarly to the collateral economy, there is no need to explicitly write down the profit maximization for the representative financial intermediary in this economy because there is no bundling in this economy.

The market clearing constraints for securities, and spot trades are as follows:

$$
\begin{aligned}
\theta_{0}^{c}+\theta_{0}^{e} & =0, \\
\theta_{t s}^{c}+\theta_{t s}^{e} & =0, \forall t=1,2 ; s=1,2, \\
\tau_{c s}^{c}+\tau_{c s}^{e} & =0, \forall s=1,2, \\
\tau_{k s}^{c}+\tau_{k s}^{e} & =0, \forall s=1,2 .
\end{aligned}
$$

Definition 9. A competitive equilibrium with fire sales is a specification of allocation $\left(\mathbf{c}^{h}, \theta^{h}, \tau^{h}, \mathbf{y}^{h}\right)_{h=c, e}$ and prices $\left(P_{t s}, \tilde{p}_{s}\right)$ such that

(i) for each consumer $c,\left(\mathbf{c}^{c}, \theta^{c}, \tau^{c}, \mathbf{y}^{c}\right)$ solves the utility maximization problem, Program (14), taking prices $\left(P_{t s}, \tilde{p}_{s}\right)$ as given;

(ii) for each entrepreneur $e,\left(\mathbf{c}^{e}, \theta^{e}, \tau^{e}, \mathbf{y}^{e}\right)$ solves the utility maximization problem, Program (15), taking prices $\left(P_{t s}, \tilde{p}_{s}\right)$ as given;

(iii) markets for securities and spot trades clear; 178-181 hold. 
As in the general model, the social planner's problem takes into account the fact that the spot-market-clearing prices $\tilde{p}_{s}=f^{\prime}\left(y_{s}^{c}\right)$ is a function of agents' choices of capital $y_{1 s}^{c}$, which in turn depends on entrepreneur's choices in period 0 including $y_{0}^{e}$ and $\theta_{1 s}^{e}$. We can now write

$$
\tilde{p}_{s}=p_{s}\left(y_{0}^{e}, \theta_{1 s}^{e}\right), \forall s=1,2
$$

These constitute the consistency constraints in this model.

The social planner's problem in this economy is as follows:

\section{Program 16.}

$$
\max _{\theta_{0}^{c}, \theta_{t s}^{c}, \tau_{c s}^{c}, \tau_{k s}^{c}} c_{0}^{c}+\sum_{s=1,2} \pi_{s}\left(c_{1 s}^{c}+c_{2 s}^{c}\right)
$$

subject to the production constraints $(153)-(159)$, the consumption-relationship constraints (160)-167), and the obstacle-to-trade constraints 168)-173), and the consistency constraints 182 .

\section{B.2 Hidden Information with Retrading (Diamond and Dybvig, 1983; Jacklin, 1987)}

\section{B.2.1 Basic Ingredients for the Hidden Information with Retrading Economy}

This is an economy with unobserved states or preference/liquidity shocks and retrading possibilities (e.g., Allen and Gale, 2004, Diamond and Dybvig, 1983; Farhi et al., 2009; Jacklin, 1987). Similar to the moral hazard problem, if there were no retrading possibility, then the Prescott-Townsend equilibria would have been equivalent to Pareto optima. However, this liquidity problem features externalities when agents can trade in spot/private markets ex-post creating the interaction of binding incentive constraints and the spot prices. As in Prescott and Townsend (1984b) and Farhi et al. (2009), we focus only on incentive compatible allocations (rather than sequential service constraints and no bank runs).

There is a continuum of ex-ante identical agents with total mass 1, i.e., no diversity in types so trivially $\alpha^{1}=1$. There are three periods, $t=0,1,2$. There is one physical 
commodity in each period $t=1,2$. Each agent is endowed with $e$ units of the good in the contracting period, $t=0$, and this will be an input into production functions.

Let $\eta$ be a ex-post preference/liquidity shock which defines a (idiosyncratic) state in this model. There is no loss of generality to assume that there are a finite $Q$ states, $\eta \in Q$. The shock/state is drawn at $t=1$ with $\pi(\eta)$ as the probability that an agent will receive $\eta$ shock such that

$$
\sum_{\eta=1}^{Q} \pi(\eta)=1
$$

In this sense there is ex-post diversity. Henceforth, we represent an ex-post type of an agent by his shock $\eta$. The fraction of agents of ex-post type $\omega=\eta$ is $\zeta^{1}(\omega)=\pi(\eta)$. With a continuum of agents, we also interpret $\pi(\eta)$ as the fraction of agents receiving $\eta$ shock.

To sum up, each state $\eta$ has two dated commodities; that is, the physical good in period $t=1$ or good 1 , and the physical good in period $t=2$ or good 2 . In addition, an investment decision at $t=0, \rho$, is also a commodity. Therefore, there are $L=2 Q+1$ commodities in this model.

The utility function conditional on a shock $\eta$ is given by $u\left(c_{1}, c_{2}, \eta\right)$, where $\left(c_{1}, c_{2}\right)$ is the vector of consumption allocations in period $t=1$ and $t=2$, respectively. For example, in the Diamond-Dybvig model, the shock will dictate if an agent would like to consume now or later. The utility function is assumed to be differentiable, concave, increasing in $c_{1}$ and $c_{2}$, and satisfies the usual Inada conditions with respect to $c_{1}$ and $c_{2}$. The discounted expected utility of an agent is define by:

$$
U(\mathbf{c})=\sum_{\eta} \pi(\eta) u\left(c_{1}(\eta), c_{2}(\eta), \eta\right)
$$

Following the literature, there are two technologies or assets. First, the short-term asset is a storage technology, whose return from $t$ to $t+1$ is $R_{1}$, i.e., saving one unit of the good today at $t$ will return $R_{1}$ units of the good in the next period at $t+1, t=0,1$. The second asset is the long-term asset. The long-term investment must be taken at $t=0$, and its return $R_{2}$ will be realized at $t=2$. We assume that the long-term asset is more productive than the short-term asset, i..e, $R_{2}>R_{1}$. For simplicity, returns here are deterministic, i.e., no aggregate shocks. 
There is no loss of generality to assume that an agent must decide how much to invest in the short-term and the long-term assets at the beginning $t=0$. Let $\rho$ be the fraction of initial endowment invested in the short-term asset; that is, $\rho e$ is the total amount invested in the short-term asset, and $(1-\rho) e$ is the total amount invested in the long-term asset. In addition, we assume that there is no option to liquidate at $t=1$, and there is no short term investment between $t=1$ and $t=2$ without loss of generality 11 . The production functions of short-term asset, $F_{1}$ (between $t=0$ and $t=1$ ), and long-term asset $F_{2}$ (between $t=0$ and $t=2$ ) are as follows:

$$
\begin{aligned}
F_{1}\left(\rho e, y_{1}\right) & =y_{1}-R_{1} \rho e=0, \\
F_{2}\left((1-\rho) e, y_{2}\right) & =y_{2}-R_{2}(1-\rho) e=0,
\end{aligned}
$$

where $y_{t}$ is an output in unit of the physical good in period $t=1,2$ regardless of the state of nature. Note however that outputs do not really vary with the preference/liquidity shocks since the shocks $\eta$ are liquidity, not productivity shocks and the distribution of shocks in the population is constant. To sum up, there are $O=2$ production functions.

\section{B.2.2 Market Structure the Hidden Information with Retrading Economy}

To be consistent with the general model, one can imagine that there are state-contingent securities $\theta_{t}\left(\eta^{\prime}\right)$ paying the single good at $t=1,2$ conditional on reported shock/state $\eta^{\prime} \in Q$. That is, security $j$ is indexed by $t$ and $\eta^{\prime}$. There are $J=2 Q$ (the number of states times the number of dates) securities available.

There is the possibility of retrade in ex post spot markets as in the moral hazard with retrading economy above. Without aggregate uncertainty, there is only one set of spot markets $(S=1)$ for good 1 and good $2\left(L^{s}=2\right)$, in which everyone participates. Let $\tau_{t}(\eta)$ be spot trade of an agent of ex-post type $\eta$ when $\eta$ is both truthfully reported and realized shock. We set the spot-market-clearing price of good 1 equal to one (the numeraire good), and let $\tilde{p}$ denote the spot-market-clearing price of good 2 , which depends on securities

\footnotetext{
${ }^{11}$ This economy is equivalent to the one in Diamond and Dybvig (1983) where banks invest in the long-term asset only, and then liquidate a fraction of the projects at $t=1$. In Allen and Gale (2004) with stochastic returns, some short term investment may be necessary at $t=1$.
} 
$\theta=\left[\theta_{t}(\eta)\right]_{t, \eta}$ and investment decision $\rho$; that is, $\tilde{p}=\tilde{p}(\theta, \rho)$.

As in the moral hazard with retrading economy, the spot markets are redundant (with complete contracts), however. Anything that can be done with spot markets can be done without them with altered security holdings. Therefore, we can omit spot trades, henceforth, though there is still an implicit shadow spot price. The consumption-relationship in this case is defined as follows:

$$
g_{t \eta^{\prime}}=y_{t}+\theta_{t}\left(\eta^{\prime}\right)-c_{t}\left(\eta^{\prime}\right)=0, \forall \eta^{\prime} ; t=1,2
$$

There are $N=2 Q$ consumption-relationship constraints.

\section{B.2.3 Trade Frictions for the Hidden Information with Retrading Economy}

With abuse of notation, we refer to $\left(c_{1}\left(\eta^{\prime}\right), c_{2}\left(\eta^{\prime}\right)\right)$ as pre-trade compensation condition on reported state/shock. Thus, the ex-post utility maximization problem at $t=1$ of an agent who reported state $\eta^{\prime}$, realized state $\eta$, and received compensation $\left(c_{1}\left(\eta^{\prime}\right), c_{2}\left(\eta^{\prime}\right)\right)$ is as follows:

$$
v\left(c_{1}\left(\eta^{\prime}\right), c_{2}\left(\eta^{\prime}\right), \eta, \tilde{p}\right)=\max _{\tau_{1}, \tau_{2}} u\left(c_{1}\left(\eta^{\prime}\right)+\tau_{1}, c_{2}\left(\eta^{\prime}\right)+\tau_{2}, \eta\right)
$$

subject to the budget constraint:

$$
\tau_{1}+\tilde{p} \tau_{2}=0
$$

taking spot price (interest rate) $\tilde{p}$ as given.

In addition, the possibility of retrade in ex post spot markets and the hidden information problem imply that an incentive compatibility (IC) or obstacle-to-trade constraint:

$$
C_{1, \eta, \eta^{\prime}}(\mathbf{c}, \tilde{p})=u\left(c_{1}(\eta), c_{2}(\eta), \eta\right)-v\left(c_{1}\left(\eta^{\prime}\right), c_{2}\left(\eta^{\prime}\right), \eta, \tilde{p}\right) \geq 0, \forall \eta, \eta^{\prime}
$$

There are $I=Q^{2}$ constraints for each $i$, and therefore with only one $i$, there are $M=Q^{2}$ obstacle-to-trade constraints in total. This will be imposed so actual and reported states will be the same.

\section{B.2.4 Competitive Equilibrium and Constrained Optimality for the Hidden In- formation with Retrading Economy}

An individual problem is as follows: 


\section{Program 17.}

$$
\max _{\rho, \theta_{t}(\eta)} \sum_{\eta} \pi(\eta) u\left(c_{1}(\eta), c_{2}(\eta), \eta\right)
$$

subject to the budget constraints

$$
\sum_{\eta} \sum_{t} P_{t}(\eta) \theta_{t}(\eta) \leq 0
$$

the production constraints (186)-(187), consumption-relationship constraints (188), and the incentive compatibility constraints (191), taking as given the spot price $\tilde{p}$ along the equilibrium path $\eta^{\prime}=\eta$.

The representative financial intermediary, dealing with all those reported states/shocks $\eta$, chooses net supply of securities $\psi=\left(\psi_{t}(\eta)\right)_{t, \eta}$ to maximize profit as follows:

$$
\max _{\psi} \sum_{\eta} \sum_{t} P_{t}(\eta) \pi(\eta) \psi_{t}(\eta)
$$

subject to feasibility constraints

$$
\sum_{\eta} \pi(\eta) \psi_{t}(\eta)=0, \forall t=1,2
$$

That is, there are $M=2$ conditions for the financial intermediary, and the security weight is a $2 \times 2 Q$-dimensional matrix $\Psi=I_{2} \otimes 1_{Q}$, where $I_{2}$ is the identity matrix with dimension 2 , $1_{Q}$ is the row of ones with dimension $Q$, and $\otimes$ is the Kronecker product operator. Similarly, the eligibility weights $\xi_{j}=\xi_{t \eta}=\pi(\eta), \forall \eta ; t=1,2$, where again $j$ is indexed by $(t, \eta)^{12}$.

The existence of a maximum to the problem requires that

$$
P_{t}(\eta)=\mu_{t}, \forall \eta ; t=1,2,
$$

\footnotetext{
${ }^{12} \mathrm{~A}$ typical vector of securities is $\psi=\left(\psi_{1}\left(\eta_{1}\right), \ldots, \psi_{1}\left(\eta_{Q}\right), \psi_{2}\left(\eta_{1}\right), \ldots, \psi_{2}\left(\eta_{Q}\right)\right)$. For example, with $Q=\left(\eta_{1}, \eta_{2}\right)$, the dimension of the vector of securities is $J=2 Q=4$; that is, $\psi=$ $\left(\psi_{1}\left(\eta_{1}\right), \psi_{1}\left(\eta_{2}\right), \psi_{2}\left(\eta_{1}\right), \psi_{2}\left(\eta_{2}\right)\right)$. Accordingly, the eligibility weights are $\xi=\left(\pi\left(\eta_{1}\right), \pi\left(\eta_{2}\right), \pi\left(\eta_{1}\right), \pi\left(\eta_{2}\right)\right)$. The security weight matrix in this case is as follows:

$$
\Psi_{2 \times 4}=I_{2} \otimes 1_{2}=\left[\begin{array}{cccc}
1 & 1 & 0 & 0 \\
0 & 0 & 1 & 1
\end{array}\right] .
$$
}


where $\mu_{t}$ is the Lagrange multiplier with respect to the $t^{t h}$ feasibility constraint (195). This clearly implies zero profit for the financial intermediary, and therefore there is no loss of generality as earlier to assume there is one representative financial intermediary.

The market clearing conditions are as follows:

$$
\theta_{t}(\eta)=\psi_{t}(\eta), \forall \eta ; t=1,2
$$

Substituting the market clearing conditions (197) into the (binding) feasibility constraints (195) gives the following resource constraints.

$$
\sum_{\eta} \pi(\eta) \theta_{t}(\eta)=0, \forall t=1,2
$$

Definition 10. A competitive equilibrium with moral hazard and retrading is a specification of allocation $(\mathbf{c}, \theta, \rho)$ for households and $\psi$ for intermediaries, and prices $(\tilde{p}, \mathbf{P})$ such that

(i) for each household, $(\mathbf{c}, \theta, \rho)$ solves the utility maximization problem, Program (17), taking prices $(\tilde{p}, \mathbf{P})$ as given;

(ii) for the financial intermediary, $\psi$ solves 194 subject to 195 , taking prices $\mathbf{P}$ as given;

(iii) markets for securities clear; 197) hold.

As in the general model, the social planner's problem takes into account the fact that the spot-market price $\tilde{p}$ depends on the choice of contracts $\theta=\left[\theta_{t}(\eta)\right]_{t, \eta}$ and the choice of investment $\rho$; that is, $\tilde{p}=\tilde{p}(\theta, \rho)$. Recall that the spot price $\tilde{p}$ clears the spot markets; that is,

$$
\sum_{\eta} \pi(\eta) \tau_{t}(\eta)=0, \forall t=1,2
$$

where $\tau_{t}(\eta)$ be equilibrium spot trade of an agent of ex-post type $\eta$, which is the solution to the utility maximization problem (189) when $\eta$ is both truthfully reported and realized shock. We do not include these conditions as resource constraints since they are redundant as discussed earlier in Section B.2.2.

The resource constraints are as follows:

$$
\sum_{\eta} \pi(\eta) \theta_{t}(\eta)=0, \forall t=1,2
$$


Note that the planner also takes into account that the choice of contracts must be consistent with actual state on the equilibrium path; that is, $\theta_{t}(\eta)$ depends on (truthfully reported and realized) state. To sum up, the consistency constraint is as the following:

$$
\tilde{p}=\tilde{p}(\theta, \rho) .
$$

The social planner's problem is to choose contracts that solves the following program.

\section{Program 18.}

$$
\max _{\rho, \theta_{t}(\eta)} \sum_{\eta} \pi(\eta) u\left(c_{1}(\eta), c_{2}(\eta), \eta\right)
$$

subject to the production constraints 186-187, , consumption-relationship constraints (188), the incentive compatibility constraints (191), the resource constraints (200), and the consistency constraints 201. 